\title{
Discovery of Novel Zeolites and Multi-Zeolite Processes for p-Xylene Separation using Simulated Moving Bed (SMB) Chromatography
}

\author{
M. M. Faruque Hasan ${ }^{1, *}$, Eric L. First ${ }^{3}$, Christodoulos A. Floudas ${ }^{1,2}$
}

\begin{abstract}
We present a multiscale approach for the identification of novel zeolites as well as for the optimization of simulated moving bed (SMB) chromatographic processes for $p$-xylene separation. Our hierarchical in silico approach pertains to detailed modeling, simulation, and optimization at molecular and process scales. At the molecular scale, it includes geometric-level pore topology characterization, minimum-energy pathway based selectivity prediction, and shape-selectivity based zeolite ranking for separation of xylenes. At the process scale, first principles model-based optimization of industrial-scale SMB process with 24 columns is performed for the selection of top zeolites and optimal process conditions. We develop a generalized mixed-integer nonlinear optimization (MINLP) model which considers both process design and material selection. We also allow for different zeolites to be selected in different columns. The application of the overall framework results in the discovery of several novel zeolites for the most profitable $p$-xylene separation using SMB chromatography. The top-ranked shape-selective zeolites are OBW, MEL, MWW, MTT, OWE, FER, SZR, IMF, TON and LAU, which have not been considered in the previous literature for $p$-xylene separation. To that end, we suggest new applications for these zeolites. Our results indicate that significant increase in profit can be achieved by replacing the current adsorbents by MWW and MEL zeolites. Remarkably, a new SMB process with multiples zeolites introduced in different columns
\end{abstract}


provides the maximum profit. Such a materials-based hybrid configuration is found to significantly increase the overall $p$-xylene separation and profit compared to the cases when a single zeolite is used for the entire process. While the discovery of both new zeolites and process configurations is enabled through the proposed multi-scale systems approach, the findings depend on sound molecular models and call for experimental validation.

Keywords: Simulated Moving Bed; Multi-scale Optimization; Multi-zeolite SMB; Material Screening; Xylenes; Process Optimization. 


\section{Introduction}

p-Xylene is one of the important BTX (benzene, toluene, and xylene) aromatics with major demand in the global chemical market. It is used to produce terephthalic acid, which is a precursor to many petrochemicals such as polyethylene terephthalate fibers, resins and films. The total demand of p-xylene between 2005 and 2008 was approximately 26.0 million metric tons/year (Kulprathipanja, 2010). The demand of $p$-xylene typically increases $5-7 \%$ per year (Bender and Tinger, 2015). Refinery processes, such as catalytic reformate, pyrolysis gasoline, toluene disproportionation and coke oven light oil, are traditional sources of xylenes. Due to their growing demands, there has been also a significant interest in producing xylenes, especially $p$ xylene, from additional sources, such as the coproduction of xylenes, chemicals and/or liquid transportation fuels from the conversion of biomass and/or natural gas using methanol and dimethyl ether (Niziolek et al., 2015; Niziolek et al., 2016).

$p$-Xylene is the most commercially sought chemical among the xylene isomers. However, the separation of pure $p$-xylene from the mixed xylenes ( $p$-xylene, $m$-xylene, $o$-xylene, and ethylbenzene) is a challenging task because of close boiling points (See Table 1). Energy and capital intensive solvent extraction and crystallization processes (Fabri et al., 2001) were the major technologies before the simulated moving bed (SMB) chromatography emerged as the most promising technology for the separation of $p$-xylene (Broughton and Gerhold, 1961; Broughton, 1978; Broughton and Gembicki, 1984). A series of experimental works by Ching, Ruthven and co-workers (1985, 1987, 1988) provided early information on SMB-based chemicals separation. Continuous operation, less solvent consumption, smaller equipment size, reduced down time, scale-up, lower investment costs and higher yields have made SMB the technology of choice for $p$-xylene separation (Rodrigues et al., 2015; Proll and Küsters, 1998). Several SMB-based processes (e.g., Parex, Aromax, Eluxyl) exist for xylene separation.

[Table 1 about herer]

An SMB process consists of a set of fixed-bed columns of uniform cross-section and length, which are packed with solid adsorbent material and arranged in a layered configuration inside an adsorbent chamber (Figure 1). In many cases (e.g., Parex process), the columns are not separate, instead a single column is used while the column is divided into multiple segments. The working 
principle of an SMB process follows the preferential adsorption and desorption of one component over others onto the microporous adsorbent surfaces. The adsorption occurs due to a concentration driving force between the solid and fluid phases. While the feed stream provides the necessary driving force for adsorption for the desired xylene isomer, a desorbent (e.g., $p$ diethyl benzene ( $p \mathrm{DEB})$, or toluene) is injected to facilitate the desorption process. $p$-Xylene is collected as an extract, while the other components are taken away from the system as raffinate. The two incoming fluid streams (feed and desorbent) and the two outgoing fluid streams (raffinate and extract) typically divide the SMB chamber into four zones (I, II, III, and IV), however more complex arrangement is possible (Silva et al., 2015). Each zone may have the same or different number of columns. For effective separation, a counter-current motion of the fluid and the adsorbent-packed columns is sought. Unlike the motion in a true moving bed (TMB) where the solid adsorbent is required to move, the counter-current motion of fluid and solid in a SMB is mimicked by changing the positions of the injection and collection points in a discrete interval using a rotary valve that controls the flows (Figure 1a). The switching of columns is made in the direction of the fluid flow. Depending on the switching, each column acts as both adsorber and desorber in a cyclic fashion. This makes the SMB a cyclic process. However, unlike most adsorption-based cyclic processes, such as pressure swing adsorption (PSA), vacuum swing adsorption (VSA) or temperature swing adsorption (TSA), a SMB process is continuous and intensified for continuous product withdrawal.

[Figure 1 about here.]

Zeolites are typically used as adsorbents in SMB-based separation. However, zeolites considered for $p$-xylene separation are still limited to faujasite (FAU)-type mono or dual metal ion-exchanged Y or X zeolites and MFI-type zeolites (e.g., ZSM-5). It is now well-established that the performance of an adsorption-based process, including SMB, depends on both the selection of process conditions and the selection of adsorbent materials (Hasan et al., 2013; First et al., 2014; Liu et al., 2016). To this end, the following questions arise:

- Q1: Materials-centric: How to identify the best zeolite for $p$-xylene separation?

- Q2: Materials- and process-centric: How to simultaneously select the best zeolite and optimize a SMB process for cost-effective $p$-xylene separation? 
Numerous SMB configurations can be obtained by either changing the number of columns in each zone, or by loading the columns with different materials, or both. In Figures 2(a-d), for example, four different SMB configurations are shown with fixed/variable number of columns and single/multiple adsorbent materials. It is, however, challenging to combine material selection with process optimization. The SMB process is complicated by the complex interplay of a large number of decision variables. Material screening with rigorous process optimization is even more challenging, as it pertains to (i) the estimation of equilibrium and kinetic properties of the adsorbent at the material scale, (ii) making discrete decisions to select the appropriate adsorbent, and (iii) making continuous decisions to select the optimal flow rates and operating conditions by solving a large-scale nonlinear process optimization problem to optimality. Despite being an established industrial process, to the best of our knowledge, no work has been reported in the literature which considers the SMB process optimization in tandem with adsorbent selection to truly optimize the SMB technology as a whole. Hasan et al. (2013) introduced a hierarchical computational approach that combines materials screening with process optimization for adsorption-based separation processes, which led to novel materials for cost-effective $\mathrm{CO}_{2}$ capture. Recently, the multi-scale approach has been applied to identify novel zeolites for natural gas purification (First et al., 2014), and hydrogen sulfide removal (Liu et al., 2016).

[Figure 2 about here.]

In this work, we introduce a systematic in silico approach for the simultaneous SMB process optimization and adsorbent selection for cost-effective separation of $p$-xylene from $\mathrm{C}_{8}$ mixtures. The approach includes a computational framework that effectively combines discovery and/or selection of materials and process systems to effectively screen large databases of microporous materials capable of separation with low cost, and high purity and recovery. Using this framework, we identify novel zeolites that have not been previously considered for industrial separation of $p$-xylene using SMB chromatography. The novel contributions of our work include:

(i) a multi-scale approach for the discovery of novel zeolites and processes for $p$ xylene separation,

(ii) geometric-level pore topology characterization via ZEOMICS (First et al., 2011), and shape-selectivity based zeolite ranking for $p$-xylene, 
(iii) combined use of microscopic shape selectivity and process economics for zeolite screening for $p$-xylene separation,

(iv) a new mixed-integer nonlinear (MINLP) optimization formulation for the simultaneous selection of materials and process optimization, which also allow for different zeolites to be selected in different columns.

(v) calculation of investment and operating costs, and profits to evaluate the performance of SMB-based $p$-xylene separation,

(vi) discovery of several novel zeolites for $p$-xylene separation, which have not been considered in previous studies, and

(vii) novel design of multi-zeolite SMB processes.

The article is organized as follows. In Section 2, we discuss the recent works related to SMB process optimization and material development. In Section 3, we provide a detailed description of our multi-scale approach for cost-effective $p$-xylene separation. The molecular scale analysis for materials-centric screening of zeolites is outlined in Section 3.1., while a detailed description of the SMB process optimization scheme for final cost-based ranking is provided in Section 3.2. The main results and discussion on top materials for $p$-xylene separation are presented in Section 4.

\section{Background}

One can design a SMB process at least in two ways for xylene separation. The more simplistic approach is based on the equilibrium theory or the so-called triangle theory (Storti et al., 1993; Mazzotti et al., 1994; Mazzotti et al., 1997). While it is convenient to apply equilibrium theory at the conceptual level, this approach neglects the mass transfer resistances and axial dispersion inside the columns, and considers infinite efficiency of the SMB column. It is important to consider diffusion-controlled mass transfer for xylene separation. In certain zeolites, such as ZSM-5, the diffusivity of $p$-xylene can be more than a thousand times higher than the diffusivities of other xylene isomers (Wei, 1982). A more rigorous design relies on the detailed modeling of the SMB process under mass transfer limitations. Early works on the modeling and simulation of SMB systems include the works by Ruthven and Ching (1989), Charton and 
Nicoud (1995), Storti et al. (1989, 1993, 1995), Proll and Küsters (1998), and Dünnebier and Klatt (1999), among others. Significant advances on the modeling and simulation of large-scale SMB-based $p$-xylene separation was reported by Rodrigues and co-workers (Azevedo and Rodrigues, 1999; Minceva and Rodrigues, 1999, 2002, 2005; Gomes et al., 2008; Silva et al., 2015).

A SMB process is inherently dynamic and never reaches a steady state, but rather achieves a cyclic steady state (CSS), where the concentration follows the same dynamic profile at each cycle. At CSS, the profiles at the beginning of a cycle are identical to those at the end of the cycle. A SMB process undergoes a transient operation for many cycles until it reaches CSS. The performance of a cyclic process should be evaluated and optimized at CSS, which makes the optimization of SMB processes a challenging task. Karlsson et al. (1999) proposed a mixed integer linear optimization (MILP) model for SMB optimization, where the bilinearities in the original model are transformed into a linear form according to Floudas (1995). Dünnebier et al. (2000) presented a mathematical design and optimization strategy for SMB chromatographic processes in general and SMB reactors in particular, while considering rigorous dynamic process model and a detailed cost function. Karlsson (2001) proposed a mathematical programming based optimization of a sequential-simulated SMB process. Lim and Jorgensen (2004) proposed a multilevel strategy for determining optimal flow rates and cycle times while minimizing the desrobent consumption. Minceva and Rodrigues (2005) proposed a method based on "separation volume" to first maximize the productivity and then minimize the desrobent consumption in a sequential manner.

The adsorption-based SMB operation can be accurately described by a set of Nonlinear Algebraic and Partial Differential Equations (NAPDEs). However, such NAPDE-based models are difficult to simulate and optimize. Emet and Westerlund (2004) modeled the dynamics of a chromatographic process as a boundary value problem that was solved, repeatedly within an optimization framework, using finite difference method. They also compared several mixed integer nonlinear programming (MINLP) formulations to solve a cyclic chromatographic separation problem. Kawajiri and Biegler (2006a) applied a full discretization approach in both spatial and temporal domains to convert the original model into a large-scale nonlinear programming (NLP) problem for asymmetric operation and cycle design (Kawajiri and Biegler, 
2006b), and superstructure-based SMB synthesis with time-variant flow rates (Kawajiri and Biegler, 2006c; Kawajiri and Biegler, 2008). Kawajiri and co-workers (Bentley at al., 2013; Bentley and Kawajiri, 2013; Sreedhar and Kawajiri, 2014) developed a prediction-correction method using startup data, isotherm model selection, and parameter estimation to update SMB model parameters and remove model mismatch while performing process optimization. A novel surrogate-based and grey-box constrained optimization approach has been put forward by Hasan et al. (2012b) to solve NAPDE models for cyclic separation processes, and has been applied to adsorption-based carbon capture (Hasan et al., 2013, 2014, 2015), natural gas purification (First et al., 2014) and hydrogen sulfide removal processes (Liu et al., 2016). Li et al. (2014) also proposed a proper orthogonal decomposition (POD)-based surrogate modeling and optimization framework for SMB chromatography. Recently, Boukouvala et al. (2015) developed a global optimization strategy for general constrained grey-box models towards optimizing the original NAPDE models that represent adsorption-based separation processes with cyclic operation.

Several works considered multiobjective optimization of SMB operations. For instance, Zhang et al. (2002) proposed a genetic algorithm-based multiobjective framework for SMB and Varicol processes. Zhang et al. (2003) performed similar multiobjective optimization to maximize both the $p$-xylene extract purity and productivity by considering the total feed concentration, the size of the packing material, and the total number of columns. Kurup et al. (2005) obtained Pareto optimal solutions for SMB and Varicol processes using a genetic algorithm. Recently, Agrawal and Kawajiri (2015) reported a multi-objective study on ternary separations using multicolumn chromatography with many operational alternatives. It is important to note that, irrespective of the approach being single-objective or multiobjective, similar process models are used in most studies. While multiobjective optimization provides multiple equally good solutions, a single condition needs to be determined at the end for actual implementation.

Microporous materials, particularly zeolites, have played important role in xylene separation (Santos et al., 2011). However, most zeolites used for the SMB-based $p$-xylene separation are limited to faujasite (FAU)-type mono or dual metal ion-exchanged Y or X zeolites (Neuzil, 1976; Zinnen, 1992; Hotier et al., 1999; Ruthven and Goddard, 1986; Paludetto et al., 1987; Cavalcante et al., 1997; Minceva and Rodrigues, 2004), and MFI-type zeolites (Yan, 1989; Sakai 
et al., 2001). The studies on metal-organic frameworks (MOFs) are even more limited, except for HKUST-1, MIL-53(Al), and MIL-47 (Alaerts et al., 2007). Silva et al. (2012) proposed a method to quickly evaluate the suitability of faujasite zeolite for $p$-xylene separation based on experimental results obtained from the breakthrough curves, namely the eluted volumes and the feed concentrations. First et al. (2013) proposed an optimization based predictive framework for the screening of shape-selective zeolites and MOFs for several separation applications including xylenes. However, they did not consider the performance of these zeolites when applied in an actual SMB process. While significant work has been done in SMB process optimization, no literature has addressed the simultaneous material selection and process optimization towards developing a more profitable SMB technology for xylene separation.

\section{Multiscale in silico Framework}

We have developed a hierarchical computational screening approach that combines discovery of zeolitic adsorbents with optimization of SMB-based separation processes. The overall approach is shown in Figure 3. The framework encapsulates a multi-scale analysis which pertains to atomistic calculations for the geometric characterization of zeolite pore systems, screening of candidate zeolites from the universe of existing zeolites using shape selectivity, and process optimization using detailed mathematical models of the SMB process to calculate profit, which represents the final ranking criterion. A detailed description of the method at each scale is provided in Sections 3.1 and 3.2.

[Figure 3 about here]

\subsection{Molecular Scale: Pore Characterization, and Screening based on Shape Selectivity}

The transport and adsorption of xylene molecules inside a zeolite are affected by their shapes and sizes, as well as by the pore characteristics of the zeolite framework. Therefore, we start our multiscale screening procedure (shown in Figure 3) with pore characterization for the existing zeolite structures taken from a zeolite database (First et al., accessed on August 15, 2015). ZEOMICS - a three dimensional pore characterization method (First et al., 2011) - is used to perform geometric characterization. Starting from the crystallographic data of a zeolite, 
ZEOMICS applies graph, geometry, and optimization algorithms to identify portals, channels, cages, and their connectivity. These provide a comprehensive description of the void spaces within a zeolite that guest molecules can access. The description includes pore size distribution, accessible volume, accessible surface area, largest cavity diameter (LCD), and pore limiting diameter (PLD).

The 3-D geometric-based characterization allows the calculation of shape selectivity of $p$ xylene with respect to other isomers in a mixture. The three-dimensional shape selectivity of zeolites considers the energetic cost of transport through possible pathways. In the case of a binary gas mixture, shape selectivity describes the difference in energetic cost of transport of two gases through a zeolites pores and their networks due to strain and distortion caused by shape and size (Gounaris et al., 2006a,b; Gounaris et al., 2009; First et al., 2013). Depending on the energetic cost, $E$, of transport, a guest molecule may have free passage $(E=0)$, hindered diffusion (low $E$ ), or no passage (high $E$ ). The energetic cost for a molecule to traverse a pathway through a $3 \mathrm{D}$ porous network is calculated by taking the maximum portal activation energy, $E_{a}$, along the pathway. From this, we identify the energy of the minimum energy pathway, $E_{P}$, as suggested by First et al (2011). Shape selectivity, $S \in[0,1]$ of $p$-xylene over another isomer ( $m$-xylene or $o$-xylene) is then calculated as the absolute difference in Boltzmann factors of the minimum pathway energies of $p$-xylene and the other molecule:

$$
\begin{aligned}
& S_{p X / m X}=\left|\exp \left(-\frac{E_{p}^{p X}}{R T}\right)-\exp \left(-\frac{E_{p}^{m X}}{R T}\right)\right| \\
& S_{p X / o X}=\left|\exp \left(-\frac{E_{p}^{p X}}{R T}\right)-\exp \left(-\frac{E_{p}^{o X}}{R T}\right)\right|
\end{aligned}
$$

where, $S_{p X / m X}$ and $S_{p X / o X}$ are the shape selectivity of $p$-xylene over $m$-xylene and $o$-xylene, respectively. To evaluate structures, we calculate the shape selectivity between $p$-xylene and its other two isomers separately, and then combine them using a geometric mean (First et al., 2013):

$$
S=\sqrt[2]{S_{p X / m X} S_{p X / o X}}
$$

A value of $S$ close to 0 indicates low selectivity (i.e., both molecules have similar energetic costs), and a value close to 1 indicates high selectivity (i.e., one molecule can traverse almost freely, whereas the other is severely hindered). The higher the value of $S$ for $p$-xylene is in a 
zeolite, the more selective the zeolite is toward $p$-xylene, based on its shape and size, over other isomers. In the proposed hierarchical framework, we select the most shape-selective zeolites using a cutoff shape selectivity value of 0.70 for further screening based on their performance in a SMB process.

\subsection{Process Scale: SMB Process Modeling \& Optimization}

The purpose of process modeling and optimization is to evaluate and compare the performances of the top shape-selective zeolites for $p$-xylene separation. The final ranking is done based on profit. We consider an industrial SMB process, as shown in Figure 4a with 24 columns. Based on the arrangement of the incoming and outgoing streams, the SMB chamber has four zones (Figure 4b), where each zone consists of multiple columns packed with a zeolite. Note that in principle each column may be packed with a different zeolite, even though this has not been reported in the literature. We consider a mixed feed with five components, namely $p$-xylene, $m$-xylene, $o$ xylene, ethylbenzene, and $p$-DEB (desorbent).

[Figure 4 about here]

\subsubsection{First Principles Model}

We characterize the fundamental adsorption, desorption and mass transfer inside a SMB-based chromatographic separation column and its dynamic behavior using a rigorous first-principles model. The mathematical model considered here is similar to that described by Pais et al. (1998). Similar models have been used for SMB for various applications (Minceva et al., 2003; Kurup et al., 2005; Araujo et al., 2006a,b; Kawajiri and Biegler, 2006a,b,c; Li et al., 2014). In this work, we expand the SMB model to include the selection of adsorbent materials towards simultaneous process synthesis and material screening. We also allow for different zeolites to be selected in different columns. We consider an isothermal and isobaric 1-dimensional model of the SMB chamber where the concentration of each component varies along the column length $(z-$ direction). Isothermal and isobaric adsorption is a reasonable assumption in SMB operation, especially when the bulk fluid phase is liquid. Since SMB is a cyclic process, the concentrations change with both space and time. The major assumptions of the process model are:

1. SMB operation is isobaric and isothermal. 
2. There are no radial variation in concentration for components in both the fluid and solid phases.

3. The flow inside a column can be characterized by an axially disperse plug-flow model with limited mass-transfer.

4. A linear driving force (LDF) approximation is adequate to describe the mass transfer in the adsorbent.

5. The boundary conditions for the mass balance equations follow from the operating conditions for the column boundaries.

6. The multicomponent adsorption equilibrium between the fluid and solid phases is described by a multicomponent Langmuir isotherm model for which the parameters are obtained using single component data.

7. Uniform bed voidage is assumed.

8. Each column has identical length and diameter.

We now discuss the Nonlinear Algebraic and Partial Differential Equations (NAPDE)-based Model for SMB process optimization.

Sets and Indices: Let $i(1 \leq i \leq I)$ represents chemical components such as $p$-xylene, $o$-xylene, $m$-xylene, ethylbenzene, and the desorbent. Also, let $n\left(1 \leq n \leq N_{T}\right)$ represents the fixed-bed columns in a SMB chamber, where $N_{T}$ is the total number of columns. Let $N_{I}, N_{I I}, N_{I I I}$, and $N_{I V}$ be the number of columns in zone I, II, III, and IV, respectively. Therefore, $N_{T}=N_{I}+N_{I I}+N_{I I I}+N_{I V}$. We also consider the set of shape-selective zeolites as candidate adsorbents for the SMB process. Let, $m(1 \leq m \leq M)$ represents a candidate zeolite. Therefore, the pool of zeolites consists of $M$ materials. The sets are summarized as follows:

$\begin{array}{lll}i & \text { component } & 1 \leq i \leq I \\ n & \text { column } & 1 \leq n \leq N_{T} \\ m & \text { material } & 1 \leq m \leq M\end{array}$

Parameters: The following parameters are defined:

$P U^{\mathrm{min}}:$ minimum specified purity of product $p$-xylene

$R E^{\text {min }}:$ minimum specified recovery of product $p$-xylene

$F^{\text {in }}$ : total feed flow rate, $\mathrm{kg} / \mathrm{min}(15 \times 60)$ 
$\varepsilon_{b}: \quad$ voidage

$K_{h}$ : $\quad$ mass transfer coefficient, $2 /$ min

$\rho$ : $\quad$ density of solid adsorbent, $1390 \mathrm{~kg} / \mathrm{m}^{3}$

$q_{i}^{\text {max }}:$ saturation adsorption loading of component $i$

$P e$ : Péclet number

$C_{i, t}^{F}$ : concentration of component $i$ in the feed at time $t$

$C^{D}{ }_{i, t}$ : $\quad$ concentration of component $i$ in the desorbent at time $t$

$D^{a x}: \quad$ axial diffusivity $\left(\mathrm{m}^{2} / \mathrm{s}\right)$

$K_{i}$ : $\quad$ isotherm parameter of component $i\left(\mathrm{~m}^{3} / \mathrm{kg}\right)$

$N_{T}$ : Total number of column (typically 24$)$

$\Omega: \quad$ column arrangement for four zones, $N_{I} / N_{I I} / N_{I I I} / N_{I V}$ (typically 6/9/6/3)

D: $\quad$ column diameter, $\mathrm{m}$

Decision Variables: The continuous decision variables for SMB process optimization are as follows:

$$
\begin{array}{ll}
u_{t}^{D}: & \text { desorbent velocity, } \mathrm{m} / \mathrm{min} \\
u_{t}^{E}: & \text { extract velocity, } \mathrm{m} / \mathrm{min} \\
u_{t}^{F}: & \text { feed velocity, } \mathrm{m} / \mathrm{min} \\
u_{t}^{R}: & \text { raffinate velocity, } \mathrm{m} / \mathrm{min} \\
u_{t}^{I V}: & \text { zone IV velocity, } \mathrm{m} / \mathrm{min} \\
t_{s:} & \text { switching time, } \mathrm{min} \\
L: & \text { column length, } \mathrm{m}
\end{array}
$$

Note that not all velocities are independent. For instance, only one of the four zone velocities can be varied independently when all the incoming and outgoing stream velocities $\left(u_{t}^{D}, u_{t}^{F}, u_{t}^{E}\right.$, and $u_{t}^{R}$ ) are fixed. Following Kurup et al. (2005), we consider $u_{t}^{I V}, u_{t}^{D}, u_{t}^{F}, u_{t}^{E}$, and $u_{t}^{R}$ to be independent variables. This makes $u_{t}^{I}, u_{t}^{I I}$, and $u_{t}^{I I I}$ to be dependent on the independent velocities through mass conservation.

System Variables: We consider each variable inside the columns to be a function of both space (along the column length) and time. To denote this, we first define 
$l$ axial coordinate along the column length

$t$ : time coordinate

The following system variables, which are functions of $l$ and $t$, are defined:
$u_{n}(t)$
fluid velocity in column $n$
$C_{i, n}(l, t):$
fluid phase concentration of component $i$ in column $n$
$q_{i, n}(l, t)$ :
actual solid loading of component $i$ in column $n$
$q_{i, n}^{e q}(l, t): \quad$ equilibrium solid loading of component $i$ in column $n$
$C_{i, n}^{i n}(t): \quad$ boundary value of fluid phase concentration of component $i$ at $\mathrm{L}=0^{+}$

Dimensionless Groups: It is advantageous to represent the NAPDE model in dimensionless forms (Hasan et al., 2012b; Hasan et al., 2013; First et al., 2014; Liu et al., 2016). To this end, we define the following dimensionless variables.

$$
z=\frac{l}{L} ; \quad \tau=\frac{t}{t_{s}} ; \quad \alpha=K_{h} ; \quad P e_{n}=\frac{u_{n} L}{D_{n}^{a x}} ; \quad \psi_{n}=\frac{u_{n} t_{s}}{L}
$$

Therefore, when $l=0, z=0$; when $l=L, z=1$; when $t=0, \tau=0$; when $t=t_{s}, \tau=1$. The following equations and constraints describe the SMB model considered in this work.

Component Balances: The following two equations (Eqs. 5-6) result from the component mass balance over a volume element of column $n$ and inside the adsorbent particles, respectively. In our model, accumulation of mass in both fluid phase and solid particles are considered. Axial dispersion for the bulk fluid phase is also included. While the accumulation terms make the concentrations dynamically varying with time, the axial dispersion contributes to the variation over space.

$$
\begin{aligned}
& \frac{\partial C_{i, n}}{\partial \tau}+\frac{1-\varepsilon_{b}}{\varepsilon_{b}} \frac{\partial q_{i, n}}{\partial \tau}=\frac{\psi_{n}}{P e_{n}} \frac{\partial^{2} C_{i, n}}{\partial z^{2}}-\psi_{n} \frac{\partial C_{i, n}}{\partial z} \\
& \frac{\partial q_{i, n}}{\partial \tau}=\alpha\left(q_{i, n}^{e q}-q_{i, n}\right)
\end{aligned}
$$

where, $q_{i, n}^{e q}=f\left(C_{i, n}\right)$ is the adsorption equilibrium concentration, and can be described using an equilibrium isotherm model. The linear driving force (LDF) model, described by Eq. 6, assumes that the mass transfer is controlled by the macro-pore diffusion mechanism, which is the case in 
industrial SMB units for xylene separation (Silva et al., 2014, 2015). The validity of the LDF approximation in sorption processes was also studied by Rodrigues and Dias (1998).

Multicomponent Adsorption Equilibria: The multicomponent adsorption equilibria is described using a nonstoichiometric Langmuir isotherms as follows:

$$
q_{i, n}^{e q}=\frac{q_{i}^{\max } K_{i} C_{i, n}}{1+\sum_{i}^{I} K_{i} C_{i, n}}
$$

Due to the variations in space and time, we need both boundary and initial conditions for the concentrations to solve the above set of equations. We now discuss these conditions which are appropriate for SMB systems.

Boundary Conditions: We apply the Danckwerts type boundary conditions to Eq. 5 to yield

$$
\begin{array}{ll}
\left.\frac{\partial C_{i, n}(z, \tau)}{\partial z}\right|_{z=0}=P e\left(\left.C_{i, n}(z, \tau)\right|_{z=0}-C_{i, n}^{\text {in }}(\tau)\right) & \forall i, \forall n \\
\left.\frac{\partial C_{i, n}(z, \tau)}{\partial z}\right|_{z=1}=0 & \forall i, \forall n
\end{array}
$$

where, $C_{i, n}^{\text {in }}$ being the concentration of component $i$ at the inlet of column $n$, i.e.,

$$
C_{i, n}^{\mathrm{in}}(\tau)=\left.C_{i, n-1}(z, \tau)\right|_{z=1} \quad \forall i, \forall n: n \notin\left\{1, N_{I}+1, N_{I}+N_{I I}+1, N_{I}+N_{I I}+N_{I I I}+1\right\}
$$

Initial Conditions/CSS Conditions: SMB is a cyclic process where the concentration profiles inside a column are identical at the beginning and at the end of each cycle. Furthermore, since the switching of columns after every cycle proceeds in the direction of the fluid flow, the profiles of column $n$ at the beginning of a cycle are identical to those of the downstream adjacent column $(n+1)$ at the end of a cycle. These are encapsulated in the following initial conditions on the fluid phase and solid phase concentrations:

$$
\begin{array}{ll}
\left.C_{i, n}(z, \tau)\right|_{\tau=0}=\left.C_{i, n+1}(z, \tau)\right|_{\tau=1} & \forall i, 1 \leq n<N_{T} \\
\left.C_{i, n}(z, \tau)\right|_{\tau=0}=\left.C_{i, 1}(z, \tau)\right|_{\tau=1} & \forall i, n=N_{T} \\
\left.q_{i, n}(z, \tau)\right|_{\tau=0}=\left.q_{i, n+1}(z, \tau)\right|_{\tau=1} & \forall i, 1 \leq n<N_{T}
\end{array}
$$




$$
\left.q_{i, n}(z, \tau)\right|_{\tau=0}=\left.q_{i, 1}(z, \tau)\right|_{\tau=1} \quad \forall i, n=N_{T}
$$

To this end, the above initial conditions also confirm CSS.

Zone Velocity Assignment: Apart from the mass balances over a volume of each column, we also need to apply mass balances at the inlet/outlet ports located between two adjacent zones within the SMB chamber to account for the changes in flow rates due to the incoming and outgoing fluid streams. The mass balances around these ports are used to calculate the superficial velocities (flow rates divided by cross-sectional area of column) for each zone as follows:

$$
\begin{array}{ll}
\text { Zone I: } u_{n, t}=u_{t}^{D}+u_{t}^{I V} & 1 \leq n \leq N_{I}, 1 \leq t \leq T \\
\text { Zone II: } u_{n, t}=u_{t}^{D}+u_{t}^{I V}-u_{t}^{E} & N_{I}+1 \leq n \leq N_{I I}, 1 \leq t \leq T \\
\text { Zone III: } u_{n, t}=u_{t}^{R}+u_{t}^{I V} & N_{I}+N_{I I}+1 \leq n \leq N_{I I I}, 1 \leq t \leq T \\
\text { Zone IV }: u_{n, t}=u_{t}^{I V} & N_{I}+N_{I I}+N_{I I I}+1 \leq n \leq N_{I V}, 1 \leq t \leq T
\end{array}
$$

Port Concentration Balance: In addition to the velocities, we must ensure that the concentrations are balanced while the incoming and outgoing flow rates are considered. The balances around the ports also yield:

$$
\begin{array}{lc}
\text { Desorbent port: } C_{i, 1}^{\mathrm{in}}\left(u_{\tau}^{D}+u_{\tau}^{I V}\right)=C_{i, N_{T}} u_{\tau}^{I V}+C_{i}^{D} u_{\tau}^{D} & \forall i \\
\text { Extract port: } C_{i, N_{I}+1}^{\mathrm{in}}=C_{i, N_{I}} & \forall i \\
\text { Feed port: } C_{i, n}^{\mathrm{in}}\left(u_{\tau}^{D}+u_{\tau}^{I V}-u_{\tau}^{E}+u_{\tau}^{F}\right)=C_{i, n^{\prime}}\left(u_{\tau}^{D}+u_{\tau}^{I V}-u_{\tau}^{E}\right)+C_{i}^{F} u_{\tau}^{F} & \\
\forall i, \quad n=N_{I}+N_{I I}+1, n^{\prime}=N_{I}+N_{I I} & \forall i, n=N_{I}+N_{I I}+N_{I I I}+1, n^{\prime}=N_{I}+N_{I I}+N_{I I I}
\end{array}
$$

Note that Eqs. 8(c) and 11(a-d) complete the definition of $C_{i, n}^{\text {in }}$ for all $n$.

Design Specifications: Minimum Product Purity and Recovery Constraints: The product ( $p$ xylene) is withdrawn as extract. Therefore, we impose the following constraint on the extract purity to satisfy the minimum purity requirement for $p$-xylene: 


$$
P U=\frac{\int_{\tau=0}^{\tau=1} u_{\tau}^{E}(\tau) C_{i, n} d \tau}{\sum_{i^{\prime} \notin d e s o r b e n t} \int_{\tau=0}^{\tau=1} u_{\tau}^{E}(\tau) C_{i^{\prime}, n} d \tau} \geq P U^{\min } \quad i=\{p X\}, n=N_{I}
$$

where, $P u^{\min }$ is the specified minimum purity of product $p$-xylene.

A similar constraint is imposed on the minimum recovery:

$$
R E=\frac{\int_{\tau=0}^{\tau=1} u_{\tau}^{E}(\tau) C_{i, n} d \tau}{\int_{\tau=0}^{\tau=1} u_{\tau}^{F}(\tau) C_{i}^{F} d \tau} \geq R E^{\min } \quad i=\{p X\}, n=N_{I}
$$

where, $R E^{\min }$ is the specified minimum recovery of product $p$-xylene over the total amount of $p$ xylene present in the feed.

SMB Capacity calculation: The effectiveness of a zeolite depends on the amount of product that it produces, even when the SMB configuration is fixed. Since we allow the feed and extract velocities to be variables, different zeolites will produce different amounts of $p$-xylene product, which in turn will generate different revenues. The total yearly $p$-xylene production, $F$, is calculated as follows:

$$
F=\left[\int_{\tau=0}^{1}\left(\varepsilon_{b} \pi D^{2} / 4\right) u_{\tau}^{F} C_{p X}^{F}(\tau) R E d \tau\right] \frac{t_{T}}{t_{S}}
$$

where, $t_{T}$ is the total operating minutes in a year.

\subsubsection{SMB Optimization Objective}

The objective function is to maximize the yearly profit (total revenue from $p$-xylene sales minus the total annualized cost):

$$
\text { MAX } \quad P R O F I T=P \times F-(\varphi F C I+A O C)
$$

where, $P$ is the unit price of $p$-xylene, $F$ is the yearly production of $p$-xylene, $F C I$ is the fixed capital investment, and $A O C$ is the annual operating cost. The investment cost is annualized using the annualizing factor, $\varphi$ (taken to be 0.154). FCI is calculated applying the six-tenth rule as follows: 


$$
F C I=F C I_{\text {base }}\left(\frac{F}{F_{\text {base }}}\right)^{0.6}
$$

where, $F C I_{\text {base }}$ and $F_{\text {base }}$ denote the known fixed capital investment $(\$)$ and $p$-xylene production capacity (MTA, metric tons per annum) of a base SMB process, respectively. Note that this cost is not only for the xylene column, but for the entire Parex unit which includes the xylene column with rotary valve, raffinate column to separate the desorbent from the raffinate, extract column to separate the desorbent from the extract, and finishing column to separate any toluene in the product $p$-xylene (Commissaris, 2004). AOC is also calculated based on the product flow rate using linear relationship with the flow rates of a base SMB process, as follows:

$$
A O C=\sum_{u} U C_{u} * U F_{\text {base }, u}\left(\frac{F}{F_{\text {base }}}\right)
$$

where, the set $u$ denotes utility, and has the following elements:

$u \in\{$ electric power, medium-pressure steam, cooling water, and fuel fired $\}$

$U C_{u}$ is the unit cost of utility $u$, and $U F_{\text {base }, u}$ is the yearly consumption of utility $u$ in the base SMB process. All the cost parameters are obtained based on the values reported by Commissaris (2004) for the production of $p$-xylene using a UOP Parex process. These are tabulated in Table 2. All costs are converted to 2015 values using the Chemical Engineering Plant Cost Index.

[Table 2 about here]

Eqs. 4-17 completes the NAPDE model for SMB optimization for a fixed zeolite. In the following, we discuss a mixed-integer nonlinear formulation which allows for all candidate zeolites to be considered at the same time using a single model. It also allows for different zeolites to be used in different columns in tandem.

\subsection{Design of SMB Processes with Single or Multiple Zeolites: A MINLP Formulation}

We note that the parameters $K_{i}$ and $q_{i}^{\max }$ in the Langmuir model, which describes the multicomponent adsorption equilibria, depend on the property of the zeolite. $K_{i}$ and $q_{i}^{\max }$ are fixed for a fixed zeolite. They would change, if we are to select another zeolite. In this work, we 
include such selection of materials in the optimization framework to enable multi-scale decision making for both materials screening and process optimization.

We define the following binary variable to select a zeolite:

$$
y_{m, n}=\left\{\begin{array}{cc}
1 & \text { if zeolite } m \text { is selected as the adsorbent for column } n \\
0 & \text { otherwise }
\end{array}, \forall m \in M, n \in N_{T}\right.
$$

The formulation includes binary variable for each column allows for the design of a novel SMB configuration with layered beds using multiple zeolites. Note that when $M=1$, we have only one zeolite, which is the typical premise of SMB optimization in the literature. To this end, our model is generalized.

Only one zeolite is selected for each column. Therefore,

$$
\sum_{m} y_{m, n}=1
$$

To ensure that the isotherm parameters of the selected material is used in the multicomponent adsorption equilibria calculations, we impose

$$
\begin{array}{ll}
K_{i, n}=\sum_{m} k_{i, m} y_{m, n} & \forall i \in I, n \in N_{T} \\
q_{i, n}^{\max }=\sum_{m} q_{i, m}^{s a t} y_{m, n} & \forall i \in I, n \in N_{T}
\end{array}
$$

Here, the isotherm parameters $k_{i, m}$ and $q_{i, m}^{s a t}$ represent the isotherm curvature and the saturated loading capacity of component $i$ in zeolite $m$, respectively. These parameters are obtained by fitting adsorption measurement data at different concentrations. These can be obtained from experiments (e.g., Minceva and Rodrigues, 2002) or using molecular simulation (e.g., Hasan et $a l ., 2013,2014)$. Note that $K i$ and $q_{i}^{\max }$ are now variables.

The inclusion of material selection makes the overall model a Mixed-Integer Nonlinear and Algebraic Partial Differential Equation (MINAPDE) problem, as described by Eqs. 4 -20. We have considered a full discretization approach that converts the MINAPDE model into a mixedinteger nonlinear optimization (MINLP) model. Similar discretization approaches were adopted in the past by Kawajiri and Biegler (2006a,b,c). They applied a central finite difference formula for the spatial discretization and Radau collocation on finite elements for the temporal discretization. In this study, we use implicit finite difference method. This method is preferable 
as it often provides stability regardless of the choice of the length of discrete element for both spatial and temporal discretization. However, this is first-order accurate in time and second order accurate in space. Although Crank-Nicolson is second-order accurate, it involves more terms and would increase the model size. Therefore, we select an implicit finite difference method. To implement the full discretization, we define the following additional sets, parameters, and variables:

$z \quad$ spatial discretization element $1 \leq z \leq Z$

$t \quad$ temporal finite element $\quad 1 \leq t \leq T$

$\Delta z \quad$ length of discrete element for spatial discretization, $1 /(Z-1)$

$h \quad$ length of discrete element for temporal discretization, $1 /(T-1)$

$u_{n, t} \quad$ velocity inside column $n$ at time $t$

$u t_{n, t} \quad$ representing bilinear term $u_{n, t} t_{S}$

$C_{i, n, z, t}$ fluid phase concentration of component $i$ in element $z$ of column $n$ at time $t$

$Q_{i, n, z, t}$ loading of component $i$ in element $z$ of column $n$ at time $t$

$Q^{e q}{ }_{i, n, z, t}$ concentration of component $i$ in element $z$ of column $n$ at time $t$

$C_{i, n, t}^{i n}$ boundary value of concentration at $\mathrm{L}=0^{+}$

$P U$ time averaged purity

$R E \quad$ time averaged recovery

$r_{i} \quad$ slack variable representing mass balance error for component $i$

We also define the following constants:

$$
\Pi_{1}=\frac{1-\varepsilon_{b}}{\varepsilon_{b}}, \Pi_{2}=\frac{1}{P e} \times \frac{1}{\Delta z^{2}}-\frac{1}{2 \Delta z}, \Pi_{3}=\frac{2}{P e} \times \frac{1}{\Delta z^{2}}, \Pi_{4}=\frac{1}{P e} \times \frac{1}{\Delta z^{2}}+\frac{1}{2 \Delta z}
$$

With this, the time and space discretization results in the following MINLP model, P0 (Eqs. 21-49):

(P0) MAX PROFIT $=P \times F-(\varphi F C I+A O C)$

subject to:

$$
\begin{aligned}
& F C I=F C I_{\text {base }}\left(\frac{F}{F_{\text {base }}}\right)^{0.6} \\
& A O C=\sum_{u} U C_{u} * U F_{\text {base }, u}\left(\frac{F}{F_{\text {base }}}\right)
\end{aligned}
$$




$$
\begin{aligned}
& F \times t_{S}=\left[R E \sum_{t=1}^{T}\left(\varepsilon_{b} \pi D^{2} / 4\right) u_{t}^{F} C_{p X, t}^{F} h\right] t_{T} \\
& u_{n, t}=u_{t}^{D}+u_{t}^{I V} \quad 1 \leq n \leq N_{I}, 1 \leq t \leq T \\
& u_{n, t}=u_{t}^{D}+u_{t}^{I V}-u_{t}^{E} \quad N_{I}+1 \leq n \leq N_{I I}, 1 \leq t \leq T \\
& u_{n, t}=u_{t}^{R}+u_{t}^{I V} \quad N_{I}+N_{I I}+1 \leq n \leq N_{I I I}, 1 \leq t \leq T \\
& u_{n, t}=u_{t}^{I V} \quad N_{I}+N_{I I}+N_{I I I}+1 \leq n \leq N_{I V}, 1 \leq t \leq T \\
& u t_{n, t}=u_{n, t} t_{S} \quad \forall n, \forall t \\
& \frac{1}{h}\left[C_{i, n, z, t}-C_{i, n, z, t-1}\right]+\Pi_{1} \times \frac{1}{h}\left[Q_{i, n, z, t}-Q_{i, n, z, t-1}\right]=\frac{u t_{n, t}}{L}\left(\Pi_{2} C_{i, n, z+1, t}-\Pi_{3} C_{i, n, z, t}+\Pi_{4} C_{i, n, z-1, t}\right) \\
& \forall i, \forall n, 2 \leq z \leq Z-1,2 \leq t \leq T \\
& C_{i, n, z, t}=C_{i, n+1, z, t^{\prime}} \quad \forall i, 1 \leq n \leq N_{T}, 2 \leq z \leq Z-1, t=1, t^{\prime}=T \\
& C_{i, n, z, t}=C_{i, n^{\prime}, z, t^{\prime}} \quad \forall i, n=N_{T}, n^{\prime}=1,2 \leq z \leq Z-1, t=1, t^{\prime}=T \\
& \frac{1}{\Delta z}\left(C_{i, n, z+1, t}-C_{i, n, z, t}\right)=P e\left(C_{i, n, z, t}-C_{i, n, t}^{i n}\right) \quad \forall i, \forall n, z=1, \forall t \\
& \frac{1}{\Delta z}\left(C_{i, n, z, t}-C_{i, n, z-1, t}\right)=0 \quad \forall i, \forall n, z=Z, \forall t \\
& C_{i, n, t}^{i n}\left(u_{t}^{D}+u_{t}^{I V}\right)=C_{i, n^{\prime}, z, t} u_{t}^{I V}+C_{i, t}^{D} u_{t}^{D} \quad \forall i, n=1, n^{\prime}=N_{T}, z=Z, \forall t \\
& C_{i, n, t}^{i n}=C_{i, n^{\prime}, z, t} \quad \forall i, n=N_{I}+1, n^{\prime}=N_{I}, z=Z, \forall t \\
& C_{i, n, t}^{i n}\left(u_{t}^{D}+u_{t}^{I V}-u_{t}^{E}+u_{t}^{F}\right)=C_{i, n^{\prime}, z, t}\left(u_{t}^{D}+u_{t}^{I V}-u_{t}^{E}\right)+C_{i, t}^{F} u_{t}^{F} \\
& \forall i, n=N_{I}+N_{I I}+1, n^{\prime}=N_{I}+N_{I I}, z=Z, \forall t \\
& C_{i, n, t}^{i n}=C_{i, n^{\prime}, z, t} \quad \forall i, n=N_{I}+N_{I I}+N_{I I I}+1, n^{\prime}=N_{I}+N_{I I}+N_{I I I}, z=Z, \forall t \\
& C_{i, n, t}^{i n}=C_{i, n-1, z, t} \quad \forall i, \forall n: n \notin\left\{1, N_{I}+1, N_{I}+N_{I I}+1, N_{I}+N_{I I}+N_{I I I}+1\right\}, z=Z, \forall t \\
& \frac{1}{h}\left(Q_{i, n, z, t}-Q_{i, n, z, t-1}\right)=t_{S} K_{h}\left(Q_{i, n, z, t}^{e q}-Q_{i, n, z, t}\right) \quad \forall i, \forall n, \forall z, 2 \leq t \leq T \\
& Q_{i, n, z, t}=Q_{i, n+1, z, t^{\prime}} \quad \forall i, 1 \leq n \leq N_{T}-1, \forall z, t=1, t^{\prime}=T \\
& Q_{i, n, z, t}=Q_{i, n^{\prime}, z, t^{\prime}} \quad \forall i, n=N_{T}, \forall z, n^{\prime}=1, t=1, t^{\prime}=T
\end{aligned}
$$




$$
\begin{array}{ll}
Q_{i, n, z, t}^{e q}\left(1+\sum_{i=1}^{I} K_{i} C_{i, n, z, t}\right)=q_{i}^{\max } K_{i} C_{i, n, z, t} & \forall i, \forall n, \forall z, \forall t \\
P U \sum_{i \notin d e s o r b e n t} \sum_{t=1}^{T} u_{t}^{E} C_{i, n, z, t} h=\sum_{t=1}^{T} C_{i^{\prime}, n, t, t} h & i^{\prime}=\{p X\}, n=N_{I}, z=Z \\
P U \geq P U^{\min } & \\
\sum_{t=1}^{T} u_{t}^{E} C_{i, n, z, t} h=R E \sum_{t=1}^{T} u_{t}^{F} C_{i, t}^{F} h & \\
R E \geq R E^{\min } & \\
\sum_{m} y_{m, n}=1 & \\
K_{i, n}=\sum_{m} k_{i, m} y_{m, n} & \\
\frac{q_{i, n}^{\max }=\sum_{m} q_{i, m}^{s a t} y_{m, n}}{1} \leq L \leq 5 & \\
\frac{3}{u^{L}} \leq u_{t}^{I V} \leq \frac{6}{u^{U}} & \\
\frac{1}{u^{L}} \leq u_{t}^{E} \leq \frac{3}{u^{U}} & \\
\frac{2}{u^{L}} \leq u_{t} \leq 3 & \\
u^{L} & \\
u_{t} & \\
u_{t}^{F} \leq \frac{3}{u^{U}} &
\end{array}
$$

Eqs. 49(a-g) provide the necessary lower and upper bounds on the decision variables. These bounds are obtained based on the operating data of a large-scale industrial SMB process for $p$ xylene (Kurup et al., 2005).

\subsubsection{MINLP Solution Strategy}


P0 is a large-scale MINLP problem with many nonconvex terms including concave term $\left(F^{0.6}\right)$, bilinear terms $\left(F \times t_{S}, u_{n, t} t_{S}, u_{n, t} C_{i, n, z, t}, C_{i, n, t}^{i n} u_{t}^{D}, C_{i, n, t}^{i n} u_{t}^{I V}, C_{i, n, t}^{i n} u_{t}^{E}, t_{S} Q_{i, n, z, t}, t_{S} Q_{i, n, z, t}^{e q}, Q_{i, n, z, t}^{e q} C_{i, n, z, t}\right.$, $\left.u_{t}^{E} C_{i, n, z, t}, K_{i} C_{i, n, z, t}\right)$, and trilinear terms $\left(q_{i}^{\max } K_{i} C_{i, n, z, t}, P U \times u_{t}^{E} \times C_{i, n, z, t}\right)$. We observe that, it is the most difficult to satisfy the minimum purity constraints (Eqs. 44-45). Due to the sharp change in concentration profiles to achieve high-purity $p$-xylene product at a high-recovery rate, we have to use large number of discretization points. Otherwise, commercial solvers cannot find any feasible solution to the NLP subproblems. In fact, finding even a feasible solution to NLP subproblems, when the binary variables are fixed, is difficult for this problem. Our computational experience also suggests that there exist multiple solutions to the balance equations, due to the nonlinearities present. However, not all solutions are physically meaningful. For instance, it can happen that the balance constraints are satisfied, although there might be a large mass balance error for the entire SMB chamber. It is often the case that the mass balance across the entire SMB chamber is far away from satisfied. When default starting points are used, the differences between the total mass fed to the SMB system and the total mass coming out from the system is significantly large. Applying a mass balance around the entire SMB chamber, we can calculate this residual mass as follows:

$$
r_{i}=\sum_{t=1}^{T}\left(u_{t}^{F} C_{i, t}^{F}+u_{t}^{D} C_{i, t}^{D}-u_{t}^{R} C_{i, n, z, t}-u_{t}^{E} C_{i, n^{\prime}, z, t}\right) h \quad \forall i, n=N_{I}+N_{I I}+N_{I I I}, z=Z, n^{\prime}=N_{I}
$$

We also observe that in most cases, the velocity profile for the raffinate follow a trend. At the beginning the highest velocities are selected for raffinate, while the velocities decrease as time increases. We use this to direct the raffinate flows as:

$$
u_{t+1}^{R} \leq u_{t}^{R} \quad \forall t
$$

We have developed an initialization strategy to solve the problem considering that at CSS, a feasible solution to the problem should correspond to $r_{i} \rightarrow 0 \forall i$. Furthermore, to find feasible solution that satisfies the product specifications, we define the following MINLP (P1):

$$
\begin{array}{ll}
\text { MIN } \quad \sum_{i} r_{i}-P U \\
\text { s.t.: } \quad \text { Eqs. } 23-44,46-49,50-51 . \\
\quad F=F_{o}
\end{array}
$$


where, $F_{o}$ is a guess starting point for $F$. P1 can be solved to find a feasible solution to the original MINLP problem. We check whether the solution of P1 satisfies the minimum purity (Eq. 45). If it satisfies, then we use the solution as a feasible starting point for the original MINLP problem. Otherwise, we increase $Z=Z+1$, and $T=T+1$, and resolve P1 until we find a feasible solution. If there is no feasible solution found at all, we consider the zeolite to be incapable of attaining the minimum purity and minimum recover specifications, and exclude the zeolite from further analysis. With the above initialization scheme, we first solve P0 (the original MINLP model) to local optimality using DICOPT (Grossmann et al., 2002). However, while it is computationally expensive to guarantee the global optimality over the entire variable bounds, we confirm the optimality of the solution by resolving P0 to optimality with refined variable bounds using the global optimization solver ANTIGONE (Misener and Floudas, 2014a; Misener and Floudas, 2012; Misener and Floudas, 2013; Misener and Floudas, 2014b; Misener et al., 2015). The refined bounds for P0, while solving using ANTIGONE, constitute a region expanded around the local solution obtained from DICOPT. Particularly, we apply $x^{*}(1-\varepsilon) \leq x \leq x^{*}(1+\varepsilon)$, where, $x$ is a variable with the current solution $x=x^{*}$, and $\varepsilon$ is considered to be $0.05(5 \%)$.

\section{Results and Discussion}

\subsection{Single Zeolite SMB Processes}

We have applied our framework to a database of 196 zeolites. From this database, we have identified the top zeolites for $p$-xylene separation. The top 10 shape selective zeolites (framework type) are OSB-2 (OBW), ZSM-11 (MEL), MMCM-22 (MWW), ZSM-23 (MTT), UiO-28 (OWE), Ferrierite (FER), SUZ-4 (SZR), IM-5 (IMF), Theta-1 (TON), and Laumontite (LAU). Most of the zeolites that we have identified are novel materials that have not been previously proposed in the literature for xylene separation. The list of shape-selective zeolites is presented in Table 3. The largest cavity diameter (LCD), pore-limiting diameter (PLD) and portal activation energies for each of the top structures are also provided. The shape selectivities are calculated at $300 \mathrm{~K}$. The top 10 zeolites have shape selectivities of $0.96-0.71$ at $300 \mathrm{~K}$.

[Table 3 about here] 
For SMB process optimization, the feed is considered to be a typical $\mathrm{C}_{8}$ aromatics mixture containing $23.6 \%$ p-xylene, $49.7 \%$ m-xylene, $12.7 \%$ o-xylene, and $14 \%$ ethylbenzene (Kurup et al., 2005). The minimum purity and recovery of p-xylene are set to be $99 \mathrm{wt} \%$ and $97 \mathrm{wt} \%$, respectively. The adsorption isotherm parameters of these aromatics for each of the zeolites considered for SMB optimization are calculated by fitting reported isotherm data using standard maximum likelihood method. These isotherm data and plots are provided in the Supplementary Material, the isotherm parameters needed to solve the MINLP model are tabulated in Table 4. The isotherm data for the Y-zeolite is obtained from Minceva \& Rodrigues (2002). For MWW (MCM-22), $q^{\max }$ and $K_{p X}$ are obtained from isotherm data reported by Du et al. (2000), $K_{m X}$ and $K_{o X}$ are obtained from isotherm data reported by Corma et al. (1996), and we further assume that $m$-xylene and ethyl benzene have similar adsorption affinity inside MWW framework. For MEL, the adsorption data are obtained from Jacobs et al. (1981) in terms of maximum number of molecules adsorbed in a unit cell. These data are converted using the adsorption of $m$-xylene $(0.36 \mathrm{~mol} / \mathrm{kg})$ from Szoxtak (1992) as the basis. For FER, isotherm parameters are obtained based on the equilibrium data by Harrison et al. (1987). Therefore, the isotherm parameters represent either actual experiments or detailed molecular simulation results previously reported in the literature. For the cases where partial data is available, we combine selectivity information to complete the information for all components. For instance, when selectivity data and $K_{p X}$ is available but any of the $K_{m X}, K_{o X}$ or $K_{E B}$ values are missing, we use the following selectivitybased approximation:

$$
S_{a d s, p X / X} \approx \frac{q_{p X}^{e q}}{q_{X}^{e q}} \approx \frac{K_{p X}}{K_{X}}
$$

where, $S_{a d s, p X / X}$ is the adsorption selectivity of $p$-xylene over another component $X$, where $X$ can be either $m$-xylene, $o$-xylene, or ethylbenzene. The above approximation is obtained based on the following two facts: (i) adsorption selectivity is calculated as the ratio of the equilibrium solid loadings, and (ii) according to the Langmuir model (Eq. 7), the ratio of equilibrium solid loadings is equivalent to the ratio of isotherm parameters, $K$. Lastly, $p$-DEB is considered as the desorbent. Due to the lack of isotherm data for the adsorption of $p$-DEB on different zeolites, we fix the isotherm parameters of $p$-DEB to be those of $p$-DEB in $\mathrm{K}$-exchanged $\mathrm{Y}$-zeolite as reported in Minceva and Rodrigues (2002). Note that this is an assumption which needs 
refinement using experimental data. We use $q_{p-D E B}^{\max }=107.7 \mathrm{~kg} / \mathrm{kg}$, and $K_{p-D E B}=1.2935 \mathrm{~m}^{3} / \mathrm{kg}$. Since the equilibrium isotherm data are available at $453 \mathrm{~K}, 318 \mathrm{~K}$, and $373 \mathrm{~K}$ for FAU, MWW and MEL respectively, we perform the process optimization at these temperatures. We also fix the following parameters to those values used in Kurup et al. (2005): $P e=2,000 ; K_{h}=2 \mathrm{~min}^{-1}, \varepsilon$ $=0.39$, and $\rho=1390 \mathrm{~kg} / \mathrm{m}^{3}$. The SMB chamber configuration is considered be a $6 / 9 / 6 / 3$ combination zones I/II/III/IV with $D=5 \mathrm{~m}$. We consider 8500 hours of annual operation. We use 10 discretized segments for both space and time $(Z=11, T=11)$. For such discretization scheme, P0 has 96 binary variables, 45,788 continuous variables, 45,700 equations, and 331,188 non-zero elements of which 269,439 elements correspond to nonlinear terms. We allowed a maximum of 10,000 seconds for each NLP subproblem, and solved the problem on Intel ${ }^{\circledR}$ Core $^{\mathrm{TM}}$ i5 CPU 750, 2.67 GHz workstation.

\section{[Table 4 about here]}

In order to rank the individual zeolites, we have evaluated the individual performance of the top zeolites. To do this, we solve the MINLP by fixing the binary variables corresponding to a particular zeolite. Specifically, we solve 4 instances of the MINLP model, each of these instances corresponds to a SMB processes that use only MEL, MWW, Y-zeolite or FER in all 24 columns. Based on the solution, the profit-based ranking of the top zeolites follow: MWW > MEL > Y-zeolite > FER. We see that each zeolite performs differently, even at the optimum conditions. The most profitable zeolite is found to be MWW (MCM-22). The optimum $p$-xylene production from the SMB process is 48,691 MTA (a total mixed xylene feed of 212,700 MTA) with $99.2 \mathrm{wt} \%$ purity and $97 \%$ recovery of $p$-xylene from mixed xylenes. The productivity is $43.1 \mathrm{~kg}$ of $p$-xylene per hour per cubic meter of adsorbent, and the desorbent consumption is 3.7 $\mathrm{kg}$ desorbent $\mathrm{kg}$ p-xylene. The optimum separation based on MWW corresponds to total annual revenue of $\$ 43.53$ million. The FCI of the process is $\$ 25.7$ million, which corresponds to an annualized investment cost of $\$ 3.95$ million. Furthermore, the annual operating cost is $\$ 4.87$ million. Therefore, the overall annual profit is $\$ 34.71$ million.

The optimal CSS concentration profiles of the component at the end of each switching time for both the fluid phase and solid phase for the MWW-based SMB process are shown in Figure 5. The profiles are highly nonlinear. The optimum switching time is $1.85 \mathrm{~min}$. The stream velocities also play role in determining the optimal SMB operation. The optimum velocity 
profiles are shown in Figure 6. It can be noted that the velocities are adjusted to maximize the production of $p$-xylene over the entire cycle time.

[Figure 5 about here]

[Figure 6 about here]

When compared with the optimum profits of other zeolites, MWW is the best ranked zeolite with a $30.8 \%$ higher profit than Y-zeolite, and 17.2\% higher profit than MEL. While the adsorption and diffusion properties of MWW and MEL were previously studied, none of these zeolites are systematically identified or put forward for industrial separation of $p$-xylene before this study. Furthermore, we show that process economics, particularly the overall profit, should be the metric to screen materials. Despite being the most popular zeolite for $p$-xylene separation, Y-zeolite does not provide as much profit as MWW provides for 24-column SMB process. One can also observe differences in the concentration profiles for MWW (Figure 5) and Y-zeolite (Figure 7). The changes in concentrations of $p$-xylene and other components are much sharper in Y-zeolite than those in MWW. This can be attributed to the difference in equilibrium adsorption characteristics of xylenes in these two zeolites. Y-zeolite has higher equilibrium capacity for xylenes, but MWW has higher affinity to $p$-xylene than other isomers.

[Figure 7 about here]

\subsection{Multiple Zeolites SMB Processes}

We have also investigated the design of a large-scale 24-column SMB process which allows for use of multiple zeolites for $p$-xylene separation from mixed xylenes. In this case, we allow for different zeolites to be allocated in different columns. Specifically, any of the 24 columns could use any of the top three zeolites, namely MWW, MEL, and Y-zeolite. The results indicate that an SMB process with multiple zeolites yields about 2.5\%, 20.1\%, and 34\% more profits than those of SMB processes which use only MWW, MEL, and Y-zeolite, respectively. The optimum $p$ xylene production from the multi-zeolite SMB process is 49,842 MTA (a total mixed xylene feed of 217,729 MTA) with $99.7 \mathrm{wt} \%$ purity and $97 \%$ recovery of $p$-xylene from mixed xylenes. This corresponds to total annual revenue of $\$ 44.56$ million. The annualized investment cost is $\$ 4.01$ million, and the annual operating cost is $\$ 4.98$ million. While the total cost is higher than any 
single-zeolite based process, the overall annual profit is $\$ 35.56$ million, which is the highest among all processes.

The optimal design of the hybrid SMB configuration is shown in Figure 8a-b. In fact, all three zeolites are selected. MWW is selected for 12 columns (columns 10-21), Y-zeolite is selected for 9 columns (columns 1-2, and $22-24$ ), and MEL is selected for 3 columns (columns 3-5). The entire chamber can be divided into four major clusters of columns, based on the allocated zeolites. While MWW and MEL are allocated in adjacent columns, the columns with Y-zeolite are placed into two separate sections of the SMB chamber. The total number of columns in each section is also different. Therefore, the overall SMB chamber consists of 4 major sections with different zeolites. To the best our knowledge, such hybrid and layered configurations have not been reported for SMB-based xylene separation.

[Figure 8 about here]

The optimum switching time is 2.16 min, which is also the highest among all processes. The optimum length of each column is obtained to be 2.99 meters. The optimal CSS concentration profiles of the component at the end of each switching time $\left(t_{s}=2.16 \mathrm{~min}\right)$ for both the fluid phase and solid phase for the multi-zeolite SMB process are shown in Figure 8c. The profiles are highly nonlinear. In particular, the concentration profiles of $p$-xylene exhibit different trend than those for single zeolite-based processes.

There are several conceivable reasons for a multi-zeolite SMB process to be more costeffective than their single-zeolite counterparts. Firstly, xylene separation is a complex problem with multiple trade-offs between purity, recovery, energy consumption and cost. Multi-zeolite SMB processes are more effective because different zeolites bring different strengths, and a concerted effort of multiple zeolites can optimally address these trade-offs and result in better separation compared to a single zeolite-based separation. For instance, high adsorption selectivity is favorable for high purity, while high adsorption capacity is favorable for high productivity. FAU has high adsorption capacity of $p$-xylene, but do not have high adsorption selectivity of $p$-xylene over $o$-xylene and ethyl benzene. While MWW shows high selectivity of p-xylene over other isomers, it does not have high adsorption capacity. However, a combination of FAU and MWW achieves both high selectivity and capacity. Secondly, SMB is a dynamic and distributed system where the adsorption and desorption of xylenes vary with time, space and 
zeolite properties. While the optimization of single-zeolite SMB processes consider the variations in time and space, the variations in zeolite properties are only possible through using multiple zeolites. The optimization of multi-zeolite SMB not only obtains the optimal time and space changes, it also optimally selects the arrangement of different zeolites, thus enabling a significant change in the adsorption/desorption characteristics of the overall system, which results in more cost-effective separation.

The use of multiple zeolites in a single SMB process may require a refined mass transfer model to account for the difference in micropore resistances and mass transfer rates in different zeolites. To determine whether the transport into the solid phase is controlled by micropore or macropore diffusion, we would need to estimate and compare the mass transfer resistances in micropores and macropores at linear equilibrium. Computational methods such as molecular dynamics (MD) can be employed to accurately predict these to conclude whether the mass transfer is macropore or micropore controlled. For instance, Hasan et al. (2013) and Banu et al. (2013) performed MD studies on the gas adsorption and transport inside zeolites and MOFs, respectively, and independently concluded that for the selected zeolites and MOFs, the adsorption rate of small molecules (e.g., $\mathrm{CO}_{2}, \mathrm{~N}_{2}, \mathrm{H}_{2}, \mathrm{CH}_{4}$ ) is macropore diffusion controlled. The method by Hasan et al. (2013) can be used to systematically compare different mass transfer resistances and check whether the mass transfer is macropore, micropore or film controlled. The calculation of micropore resistances requires MD simulations on the gas adsorption and transport inside zeolites. Few works have used molecular simulation to study the adsorption and diffusion of xylene isomers only in selected adsorbents. Granato et al. (2014) evaluated four force fields for MOF UiO-66 and concluded that the estimation of absolute adsorption capacities can be different depending on the force field parameters for describing the electrostatic interactions, both for the single as well as for the multicomponent adsorption. Gee and Sholl (2015) proposed force fields based on density functional theory (DFT) calculations to examine the adsorption of $\mathrm{C}_{8}$ cyclic hydrocarbons in several MOFs. However, xylene isomers are much larger molecules and no accurate force-field is currently available to predict the adsorption and diffusion of xylenes in zeolites, which limit the use of molecular simulation in our current framework.

If the mass transfer is controlled by the diffusion of xylenes in the zeolite macropores, then our linear driving force (LDF)-based model with constant mass transfer coefficient $\left(K_{h}\right)$ is valid. We 
still perform a sensitivity analysis on the mass transfer coefficient $\left(K_{h}\right)$, and run the MINLP model for five different values of $K_{h}$ at 1.5, 2.0, and 2.5 for each of the three zeolites (Y-zeolite, MWW and MEL). The sensitivity results are shown in Figures 9a-b. We observe that both the purity and profit of the SMB process increase with increased mass transfer rate for all three zeolites. For instance, a $25 \%$ increase in $K_{h}$ from $2 \mathrm{~min}^{-1}$ to $2.5 \mathrm{~min}^{-1}$ increases the purity by $0.59 \%, 0.65 \%$ and $2.7 \%$ for zeolites MEL, Y-zeolite and MWW, respectively. However, the purity and profit are not equally sensitive to the mass transfer rate for all zeolites. Further research is needed for the multi-zeolite SMB processes to incorporate optimization in the presence of parameter uncertainties related to mass transfer equilibrium and kinetics.

\section{Conclusions}

We presented a multiscale approach for the discovery of novel zeolites for $\mathrm{p}$-xylene separation using SMB chromatography. We have uncovered several cost-effective zeolites for SMB-based separation of xylenes using a novel computational framework that combines material screening and process optimization. The hierarchical framework combines geometric-, atomistic-, and process-level modeling to screen a database of candidate zeolites and identify those feasible and economical for use in a SMB process. Our results indicate that significant increase in profit can be achieved by replacing the current adsorbents by MWW and MEL zeolites. Our results also indicate that, in contrast to the current industrial practice, the overall performance of SMB processes can potentially be improved using multiple zeolites. It is a layered SMB chamber with multiples zeolites that provides the maximum profit. Such multiple materials-based hybrid configurations are likely to increase the overall $p$-xylene separation and profit significantly compared to the cases when a single zeolite is used for the entire process. We demonstrated the necessity of applying a multiscale approach to identify the best materials and process conditions to increase the profits from SMB-based $p$-xylene separation. This is consistent with our recent findings for pressure swing adsorption-based carbon capture (Hasan et al., 2013), natural gas purification (First et al., 2014), and hydrogen sulfide removal (Liu et al., 2016). While our multiscale approach enables the discovery of both new zeolites and process configurations, its applicability depends on reliable data based on molecular models and/or real experiments.

\section{Acknowledgments}


The authors gratefully acknowledge financial support from the National Science Foundation (NSF EFRI-0937706, NSF CBET-1158849 and NSF CBET-1263165). 


\section{Literature Cited}

Agrawal, G., Kawajiri, Y. (2015). Full Superstructure for Multiobjective Optimization of Multicolumn Chromatography for Ternary Separations. Chem. Eng. Technol. 38(9), 16771682.

Alaerts, L., Kirschhock, C. E. A., Maes, M., van der Veen, M. A., Finsy, V., Depla, A., Martens, J. A., Baron, G. V., Jacobs, P. A., Denayer, J. F. M., De Vos, D. E. (2007). Selective Adsorption and Separation of Xylene Isomers and Ethylbenzene with the Microporous Vanadium(IV) Terephthalate MIL-47. Angew. Chem. Int. Ed., 46, 4293-4297.

Araujo, J. M. M., Rodrigues, R. C. R., Mota, J. P. B. (2006a). Optimal Design and Operation of a Certain Class of Asynchronous Simulated Moving Bed Processes. J. Chromatogr. A, 1132, $76-89$.

Araujo, J. M. M., Rodrigues, R. C. R., Mota, J. P. B. (2006b). Use of Single-Column Models for Efficient Computation of the Periodic State of a Simulated Moving-Bed Process. Ind. Eng. Chem. Res., 45 , 5314-5325.

Azevedo, D. C. S., Rodrigues, A. E. (1999). Design of a Simulated Moving Bed in the Presence of Mass-Transfer Resistances. AIChE J. 45, 956.

Baertsch, C. D., Funke, H. H., Falconer, J. L., Noble, R. D. (1996). Permeation of Aromatic Hydrocarbon Vapors through Silicalite-Zeolite Membranes. J. Phys. Chem., 100, 76767679.

Banu, A.-M., Friedlich, D., Brandani, S., Düren, T. (2013). A Multiscale Study of MOFs as Adsorbents in $\mathrm{H}_{2}$ PSA Purification. Ind. Eng. Chem. Res., 52, 9946-9957.

Bender, T.P., Tinger, R.G. (2015). Production of Para-Xylene. US Patent 20,150,175,507.

Bentley, J., Sloan, C., Kawajiri, Y. (2013). Simultaneous modeling and optimization of nonlinear simulated moving bed chromatography by the prediction-correction method. J. Chromatogr. A, 1280, 51-63.

Bentley, J., Kawajiri, Y. (2013). Prediction-correction method for optimization of simulated moving bed chromatography. AIChE J., 59(3), 736-746. 
Boukouvala, F., Hasan, M. M. F., Floudas, C. A. (2015). Global Optimization of Generalized Constrained Grey-Box Models: New Method and Its Application to Constrained PDEs for Pressure Swing Adsorption. J. Global Optim., 1-40. DOI: 10.1007/s10898-015-0376-2.

Broughton, D. B., Gerhold, C. G. (1961). Continuous Sorption Process Employing Fixed Bed of Sorbent and Moving Inlets and Outlets. U.S. Patent No. 2,985,589.

Broughton, D.B. (1978). In Kirk-Othmer Encyclopedia of Chemical Technology, Vol. 1, Wiley, New York, 3rd Ed.

Broughton D.B., Gembicki, S.A. (1984). In A.L. Myers and G. Belfort (Editors), Fundamentals of Adsorption, Engineering Foundation, New York.

Cavalcante, C. L., Jr.; Lima, V. E.; Sousa, L. G.; Alsina, O. L. S. (1997). Sorption Kinetics of Aromatics in Y Zeolite Pellets Using the Gravimetric Method. Braz. J. Chem. Eng. 14, 191.

Charton, F., Nicoud, R.-M. (1995). Complete Design of a simulated Moving Bed. J. Chromatogr. A. 702, 97-112.

Ching, C.B., Ruthven, D.M. (1985). An experimental study of a simulated counter-current adsorption system-I. Isothermal steady state operation. Chem. Eng. Sci. 40, 877.

Ching, C.B., Ruthven, D.M. (1987). Experimental study of a simulated counter-current adsorption system-V. Comparison of resin and zeolite absorbents for fructose-glucose separation at high concentration. Chem. Eng. Sci. 42, 2547 - 2555.

Ching, C.B., Ho, C., Ruthven, D.M. (1988). Experimental study of a simulated counter-current adsorption system-VI. Non-linear systems. Chem. Eng. Sci. 43, 703.

Commissaris, S. E. (2004). UOP Parex Process. In: Handbook of Petroleum Refining Processes, Third Edition. Ed.: Meyers, R. A. McGraw-Hill, New York, USA, 2004.

Corma, A., Corell, C., Pérez-Pariente, J., Guil, J. M., Guil-López, R., Nicolopoulos, S., Gonzalez Calbet, J., Vallet-Regi, M. (1996). Adsorption and catalytic properties of MCM-22: The influence of zeolite structure. Zeolites, 16(1), 7-14.

Du, H., Kalyanaraman, M., Camblor, M. A., Olson, D. H. (2000). Hydrocarbon Sorption Properties of Pure Silica MCM-22 Type Zeolite. Microporous and Mesoporous Materials, 40, 305-312. 
Dünnebier, G., Klatt, K.-U. (1999). Optimal Operation of Simulated Moving Bed Chromatographic Processes. Comput. Chem. Eng. Suppl.23, S195-S198.

Dünnebier, G., Fricke, J., Klatt, K.-U. (2000). Optimal Design and Operation of Simulated Moving Bed Chromatographic Reactors. Ind. Eng. Chem. Res. 39, 2290-2304.

Emet, S., Westerlund, T. (2004). Comparisons of Solving a Chromatographic Separation Problem using MINLP Methods. Comput. Chem. Eng. 41, 673-682.

Fabri, J., Greaser, U., Simo, T.A. (2001). Xylenes-Production, Separation and Further Processing. Ullmann's Encyclopedia of Industrial Chemistry. Wiley-VCH GmbH: Weinheim, Germany.

First, E. L., Gounaris, C. E., Wei, J., Floudas, C. A. (2011). Computational Characterization of Zeolite Porous Networks: An Automated Approach. Phys. Chem. Chem. Phys., 13, 1733917358.

First, E. L., Gounaris, C. E., Floudas, C. A. (2013). Predictive Framework for Shape-Selective Separations in Three-Dimensional Zeolites and Metal-Organic Frameworks. Langmuir. 29, $5599-5608$.

First, E. L., Gounaris, C. E., Wei, J., Floudas, C A. ZEOMICS. http://helios.princeton.edu/zeomics/, accessed on August 15, 2015.

First, E. L., Hasan, M. M. F., Floudas, C. A. (2014) Discovery of Novel Zeolites for Natural Gas Purification through Combined Material Selection and Process Optimization Approach. AIChE J. 60(5), 1767-1785.

Floudas C.A. (1995). Nonlinear and Mixed-Integer Optimization. Fundamentals and Applications. Oxford University Press.

Gee, J. A., Sholl, D. S. (2015) Prediction of adsorption properties of cyclic hydrocarbons in MOFs using DFT-derived force fields. The Journal of Physical Chemistry C. 119, 1692016926.

Gomes, P.S., Minceva, M. Rodrigues, A.E. (2008). Operation of an Industrial SMB Unit for $p$ Xylene Separation Accounting for Adsorbent Ageing Problems. Separ. Sci. Technol. 43, 1974-2002. 
Gounaris, C. E., Floudas, C. A., Wei, J. (2006a). Rational Design of Shape Selective Separation and Catalysis-I: Concepts and Analysis. Chem. Eng. Sci., 61:7933-7948.

Gounaris, C. E., Wei, J., Floudas, C. A. (2006b). Rational Design of Shape Selective Separation and Catalysis-II: Mathematical Model and Computational Studies. Chem. Eng. Sci., 61:7949-7962.

Gounaris, C. E., Wei, J., Floudas, C. A., Ranjan, R., Tsapatsis, M. (2009). Rational Design of Shape Selective Separations and Catalysis: Lattice Relaxation and Effective Aperture Size. AIChE J., 56, 611-632.

Granato, M.A., Martins, V. D., Ferreira A.F.P., Rodrigues, A.E. (2014). Adsorption of xylene isomers in MOF UiO-66 by molecular simulation. Microporous and Mesoporous Materials $190,165-170$.

Grossmann, I. E., Viswanathan, J., Vecchietti, A., Raman, R., Kalvelagen, E. (2002). GAMS/DICOPT: A Discrete Continuous Optimization Package. Washington, D.C.: GAMS Development Corp.

Harrison, I.D., Leach, H. F., Whan, D. A. (1987). Comparison of the Shape Selective Properties of Ferrierite, ZSM-5 and ZSM-11. Zeolites, 7, 21-27.

Hasan, M. M. F., Baliban, R. C., Elia, J. A., Floudas, C. A. (2012a). Modeling, Simulation and Optimization of Post-combustion $\mathrm{CO}_{2}$ Capture for Variable Feed $\mathrm{CO}_{2}$ Concentration and Feed Flow. 1. Chemical Absorption and Membrane Processes. Ind. Eng. Chem. Res. 51(48), $15642-15664$.

Hasan, M. M. F., Baliban, R. C., Elia, J. A., Floudas, C. A. (2012b). Modeling, Simulation and Optimization of Post-combustion $\mathrm{CO}_{2}$ Capture for Variable Feed $\mathrm{CO}_{2}$ Concentration and Feed Flow. 2. Pressure Swing Adsorption and Vacuum Swing Adsorption Processes. Ind. Eng. Chem. Res. 51(48), 15665-15682.

Hasan, M. M. F., First, E. L., Floudas, C. A. (2013). Cost-effective $\mathrm{CO}_{2}$ Capture based on in silico Screening and Process Optimization. Phys. Chem. Chem. Phys. 15, 17601-17618. 
Hasan, M. M. F., Boukouvala, F., First, E. L., Floudas, C. A. (2014). Nationwide, Regional and Statewide $\mathrm{CO}_{2}$ Capture, Utilization and Sequestration Supply Chain Network Optimization. Ind. Eng. Chem. Res. 53(18), 7489-7506.

Hasan, M. M. F., First, E. L., Boukouvala, F., Floudas, C. A. (2015). A Multi-scale Framework for $\mathrm{CO}_{2}$ Capture, Utilization, and Sequestration: CCUS and CCU. Comput. Chem. Eng. 81, $2-21$.

Hotier, G.; Roux, G. C.; Nguyen, T. T. (1999). Process for Separation of $p$-Xylene in $\mathrm{C}_{8}$ Aromatic Hydrocarbons with a Simulated Moving Bed Adsorption and Crystallization. U.S. Patent 5922924.

Jacobs, P. A., Beyer, H. K., Valyon, J. (1981). Properties of the End Members in the PentasilFamily of Zeolites: Characterization as Adsorbents. Zeolites, 1, 161-168.

Karlsson, S. (2001). Optimization of a Sequential-Simulated Moving-Bed Separation Process with Mathematical Programming Methods. Ph.D. Thesis. Åbo Akademi University, Åbo, Finland.

Kawajiri, Y., Biegler, L. T. (2006a). Optimization Strategies for Simulated Moving Bed and PowerFeed Processes. AIChE J. 52(4), 1343-1350.

Kawajiri, Y., Biegler, L. T. (2006b). Large Scale Nonlinear Programming for Asymmetic Design and Operation of Simulated Moving Beds. J. Chromatogr. A, 1133, 226-240.

Kawajiri, Y., Biegler, L. T. (2006c). A Nonlinear Programming Superstructure for Optimal Dynamic Operations of Simulated Moving Bed Processes. Ind. Eng. Chem. Res. 45(25), 8503-8513.

Kawajiri, Y., Biegler, L. T. (2008). Large-scale Optimization Strategies for Zone Configuration of Simulated Moving Beds. Comput. Chem. Eng. 32, 135-144.

Kulprathipanja S. (2010). Zeolites in Industrial Separation and Catalysis. Weinheim, Germany: Wiley Online Library.

Kurup, A.S., Hidajat, K., Ray, A.K. (2005). Optimal Operation of an Industrial-Scale Parex Process for the Recovery of $p$-Xylene from a Mixture of $\mathrm{C}_{8}$ Aromatics. Ind. Eng. Chem. Res. 44, 5703-5714. 
Li, S., Feng, L., Benner, P., Seidel-Morgenstern, A. (2014). Using Surrogate Models for Efficient Optimization of Simulated Moving Bed Chromatography. Comput. Chem. Eng. 67, $121-132$.

Lim, Y.-I., Jorgensen, S. B. (2004). Optimization of simulated moving bed (SMB) chromatography: A multi-level optimization procedure. In A. Barbosa-Povoa \& H. Matos (Eds.), ESCAPE-14: European Symposium on Computer Aided Process Engineering. Lisbon, Portugal: Elsevier Science.

Liu, T., First, E. L., Hasan, M. M. F., Floudas, C. A. (2016). A Multi-scale Approach for the Discovery of Zeolites for Hydrogen Sulfide Removal. Comput. Chem. Eng., 91, 206 - 218.

Mazzotti, M., Storti, G., Morbidelli. (1994). Robust design of binary countercurrent adsorption separation processes: 2. Multicomponent Systems. AIChE J. 40(11), 1825-1842.

Mazzotti, M., Storti, G., Morbidelli. (1997). Robust design of binary countercurrent adsorption separation processes: 4. Desorbent in the Feed. AIChE J. 43(1), 64-72.

Minceva, M., Rodrigues, A. E. (2002). Modeling and Simulation of a Simulated Moving Bed for the Separation of p-Xylene. Ind. Eng. Chem. Res., 41, 3454.

Minceva, M., Rodrigues, A. E. (2004). Adsorption of Xylenes on Faujasite-Type Zeolite: Equilibrium and Kinetics in Batch Adsorber. Chem. Eng. Res. and Des., 82, 667.

Minceva, M., Rodrigues, A. E. (2005). Two-level Optimization of an Existing SMB for $p$-xylene Separation. Comput. Chem. Eng. 29, 2215-2228.

Misener, R., Floudas, C. A. (2014a). ANTIGONE: algorithms for continuous/integer global optimization of nonlinear equations. Journal of Global Optimization. 59 (2-3), 503-526.

Misener, R.; Floudas, C. A. (2014b). A Framework for Globally Optimizing Mixed-Integer Signomial Programs. J. Optim. Tehory Appl. 161, 905-932.

Misener, R.; Smadbeck, J. B.; Floudas, C. A. (2015). Dynamically-Generated Cutting Planes for Mixed-Integer Quadratically-Constrained Quadratic Programs and Their Incorporation into GloMIQO 2. Optimization Methods and Software, 30(1), 215-249.

Misener, R.; Floudas, C. A. (2013). GloMIQO: Global Mixed-Integer Quadratic Optimizer. Journal of Global Optimization, 57, 3-50. 
Misener, R.; Floudas, C. A. (2012). Global optimization of mixed-integer quadraticallyconstrained quadratic programs (MIQCQP) through piecewise-linear and edge-concave relaxations. Mathematical Programming; Series B., 136, 155-182.

Neuzil, R. W. (1976). Process for Separating p-Xylene. U.S. Patent 3997620.

Niziolek, A.M., Onel, O., Elia, J.A., Baliban, R.C., Floudas, C.A. (2015). Coproduction of Liquid Transportation Fuels and $\mathrm{C}_{6} \mathrm{C}_{8}$ Aromatic from Biomass and Natural Gas. AIChE J. 61:831-856.

Niziolek, A.M., Onel, O., Floudas, C.A. (2016). Production of Benzene, Toluene, and Xylenes from Natural Gas via Methanol: Process Synthesis and Global Optimization. AIChE J. DOI: 10.1002/aic.15144.

Pais, L. S.; Loureiro, J. M.; Rodrigues, A. E. (1998). Modeling Strategies for the Enantiomers Separation by SMB Chromatography. AIChE J. 44, 561.

Paludetto, R.; Storti, G.; Gamba, G.; Carra, S.; Morbidelli, M. (1987). On Multicomponent Adsorption Equilibria of Xylene Mixture on Zeolite. Ind. Eng. Chem. Res. 26, 2250.

Proll, T., Küsters, E. (1998). Optimization Strategy for Simulated Moving Bed Systems. J. Chromatogr. A. 800, 135-150.

Rosemarie Szoxtak. (1992). Handbook of Molecular Sieves: Structures. Springer, Netherlands.

Rodrigues AE, Dias MM. (1998). Linear driving force approximation in cyclic adsorption processes: simple results from system dynamics based on frequency response analysis. Chem Eng Process. 37:489-502

Rodrigues, A.E., Pereira, C., Minceva, M., Pais, L.S., Ribeiro, A.M., Silva, M., Graca, N., Santos, J.C. (2015). Simulated Moving Bed Technology. Principles, Design and Process Applications. Oxford : Butterworth-Heinemann.

Ruthven, D.M., Ching, C.B. (1989). Counter-current and Simulated Counter-current Adsorption Separation Processes. Chem. Eng. Sci. 44, 1011-1038.

Ruthven, D. M., Goddard, M. (1986). Sorption and Diffusion of $\mathrm{C}_{8}$ Aromatic Hydrocarbons in Faujasite Type Zeolites. I. Equlilbrium Isotherms and Separation Factor. Zeolites. 6, 275. 
Sakai, H.; Tomita, T.; Takahashi, T. (2001). p-Xylene separation with MFI-type zeolite membrane. Sep. Purif. Technol. 25, 297-306.

Santos, K. A. O., Dantas Neto, A. A., Moura, M. C. P. A., Castro Dantas, T. N. (2011). Separation of Xylene Isomers through Adsorption on Microporous Materials: A Review. Brazilian Journal of Petroleum and Gas, 5(4), 255-268.

Silva, M. S. P., Moreira, M. A., Ferreira, A. F. P., Santos, J. C., Silva, V. M. T. M., Gomes, P. S., Minceva, M., Mota, J. P. B., Rodrigues, A. E. (2012). Adsorbent Evaluation Based on Experimental Breakthrough Curves: Separation of $p$-Xylene from $\mathrm{C}_{8}$ Isomers. Chem. Eng. Technol., 35(10), 1777-1785.

Silva, M.S.P., J.P.B., Mota, Rodrigues, A.E. (2014). Adsorption Equilibrium and Kinetics of the Parex' Feed and Desorbent Streams from Batch Experiments. Chemical Engineering Technology 2014, 37(9), 1541-1551

Silva, M.S.P., Rodrigues, A.E., Mota, J.P.B. (2015). Modeling and Simulation of an Industrialscale Parex Process. AIChE J. 61(4), 1345-1363.

Sreedhar, B., Kawajiri, Y. (2014). Multi-column chromatographic process development using simulated moving bed superstructure and simultaneous optimization - model correction framework. Chem. Eng. Sci., 116, 428-441.

Storti, G., Mazzotti, M., Morbidelli, M., Carra, S. (1993). Robust design of binary countercurrent adsorption separation processes. AIChE J. 39(3), 471-492.

Storti, G., Massi, M., Carra, S., Morbidelli, M. (1989). Optimal Design of Multicomponent Countercurrent Adsorption Separation Processes Involving Nonlinear Equilibria. Chem. Eng. Sci. 44, 1329.

Storti, G. Baciocchi, R., Mazzotti, M., Morbidelli, M. (1995). Design of Optimal Operating Conditions of Simulated Moving Bed Adsorptive Separation Units. Ind. Eng. Chem. Res. 34(1), 288-301.

Washburn EW. (2003). International Critical Tables of Numerical Data, Physics, Chemistry and Technology, 1st Ed. London: Knovel, Reed Elsevier. 
Wei, J. (1982). A Mathematical Theory of Enhanced para-Xylene Selectivity in Molecular Sieve Catalysts. Journal of Catalysis, 76, 433-439.

Yan, T. Y. (1989). Separation of $p$-Xylene and Ethylbenzene from $\mathrm{C}_{8}$ Aromatics Using Medium pore Zeolites. Ind. Eng. Chem. Res. 28, 572.

Zhang, Z., Hidajat, K., Ray, A.K., Morbidelli, M. (2002). Multiobjective Optimization of SMB and Vericol Process for chiral separation. AIChE J. 48(12), 2800-2816.

Zhang, Z., Mazzotti, M., Morbidelli, M. (2003). Multiobjective Optimization of Simulated Moving Bed and Vericol Process using a Genetic Algorithm. J. Chromatogr. A. 989, 95-108.

Zinnen, H. A. (1992). Zeolitic $p$-Xylene Separation with Tetrelin Derivatives as Heavy Desorbent. U.S. Patent 5107062. 


\section{List of Figures}

1. SMB technology with key process and material decisions.

2. Different SMB configurations, which can be obtained by either changing the number of columns in each zone, or by layering the beds with different materials, or both.

3. Flowchart of the multi-scale zeolite screening and process optimization method for $p$ xylene separation.

4. Schematic of the SMB process considered in this work.

5. Cyclic steady-state concentration and loading profiles at the end of each cycle for different components for MWW at the optimum conditions.

6. Optimum incoming and outgoing stream velocities for MWW.

7. Cyclic steady-state concentration and loading profiles at the end of each cycle for different components for Y-zeolite at the optimum conditions for 24-column SMB process with 6/9/6/3 configuration.

8. Design of 24-column SMB process with multiple zeolites.

9. Sensitivity of (a) purity and (b) profit of SMB-based xylene separation on mass transfer rate. 


\section{(a) SMB PROCESS FLOW DIAGRAM}
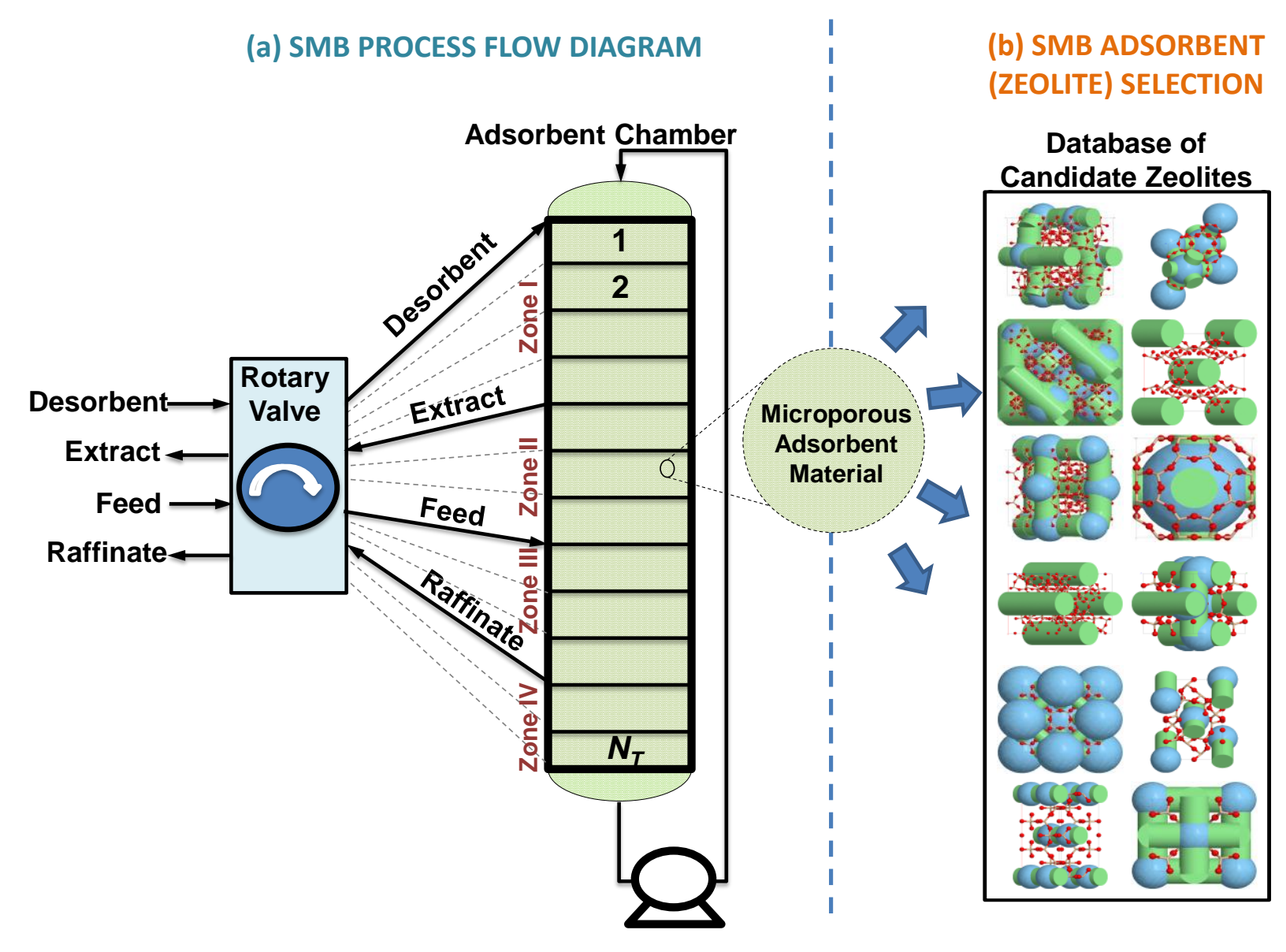

\section{(b) SMB ADSORBENT (ZEOLITE) SELECTION}

Database of Candidate Zeolites

Figure 1. SMB technology with key process and material decisions: the development of optimal SMB technology would depend on both (a) process configuration, and (b) adsorbent material selection. Depending on the material used, the performance of the SMB process can vary significantly. 
(a)

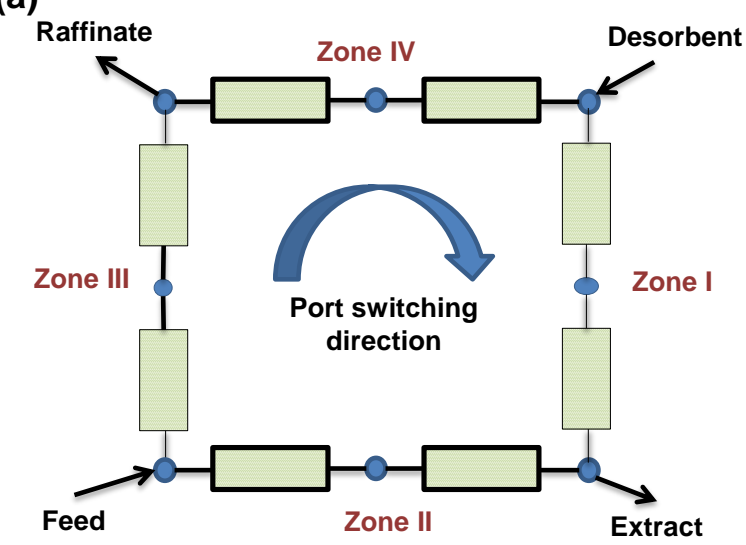

(c)

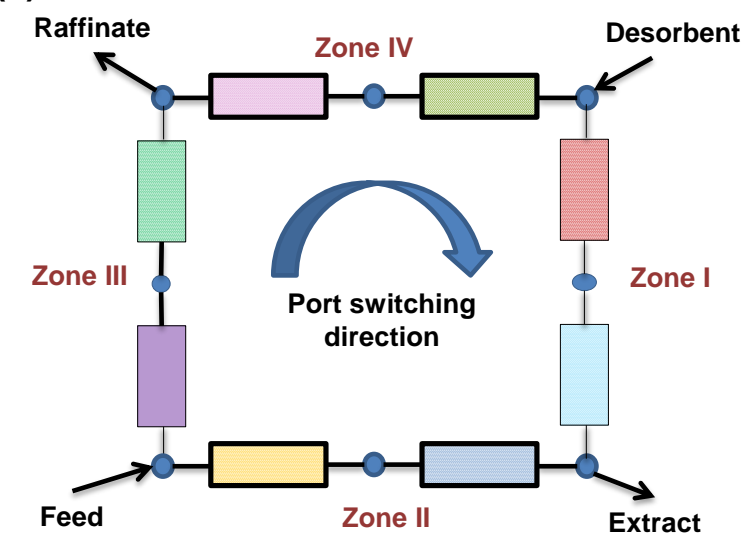

(b)

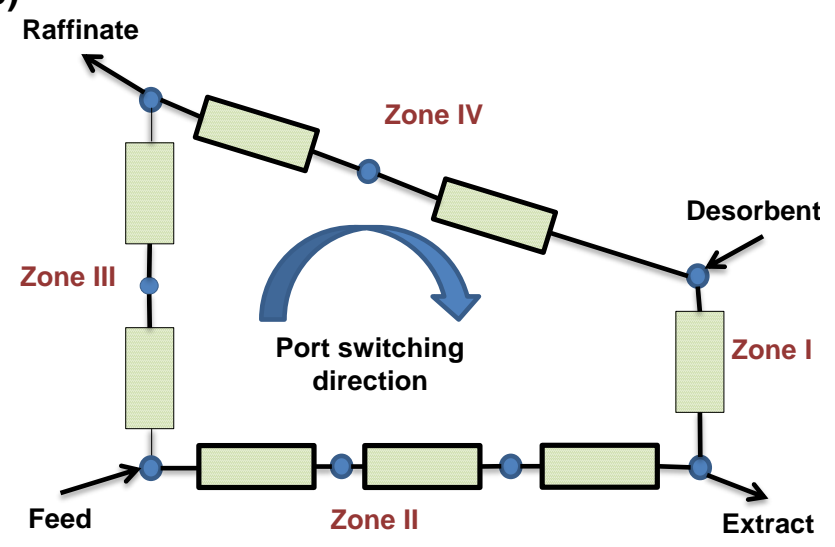

(d)

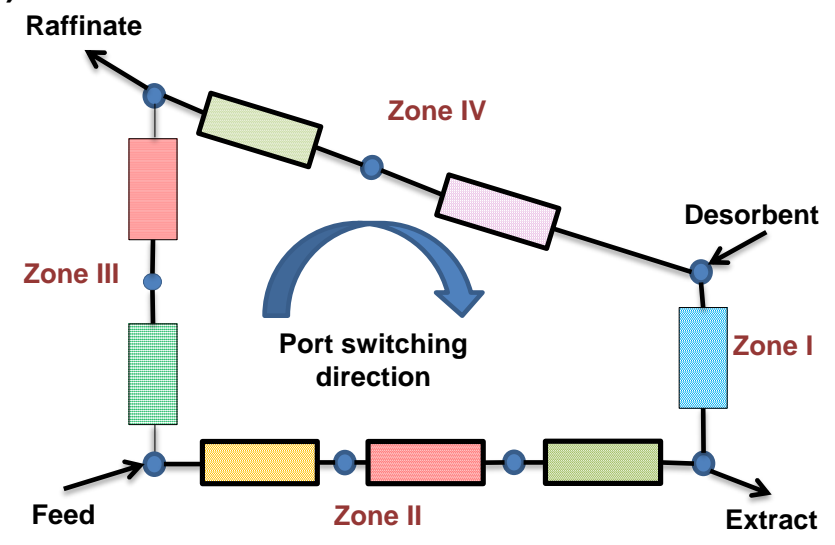

Figure 2. Different SMB configurations, which can be obtained by either changing the number of columns in each zone, or by layering the beds with different materials, or both: (a) SMB configuration with fixed number of columns and a single adsorbent material, (b) SMB configuration with variable number of columns but fixed adsorbent material, (c) SMB configuration with fixed number of columns but different materials, and (d) SMB configuration with different number of columns and different materials. Note that all four SMB configurations have eight columns in total. 


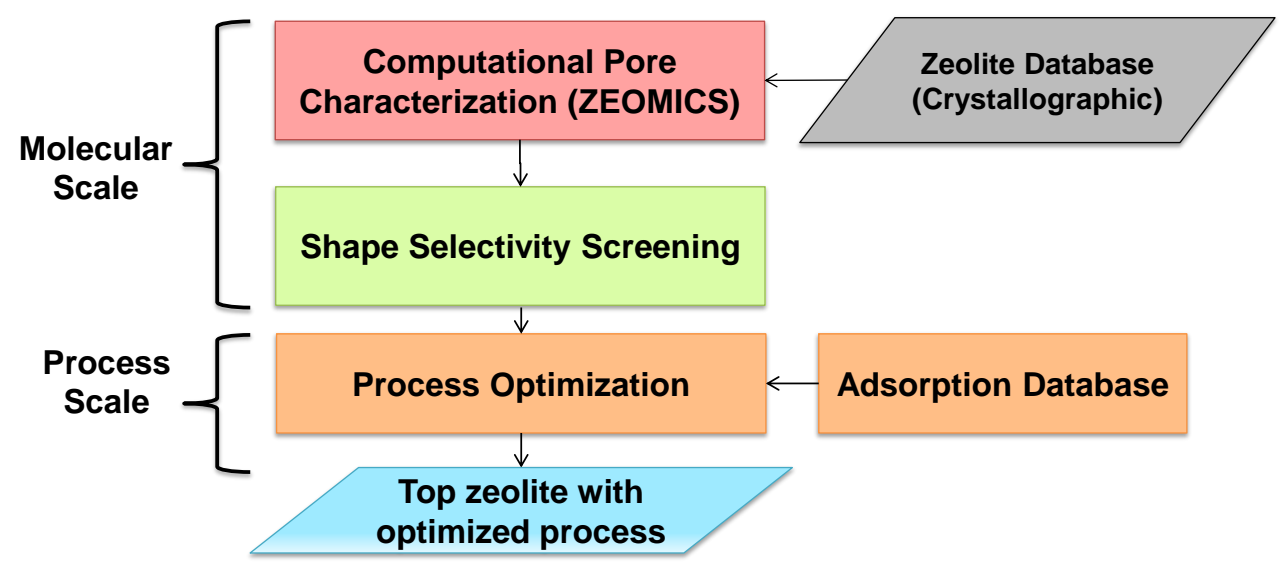

Figure 3. Flowchart of the multi-scale zeolite screening and process optimization method for $p$ xylene separation. 


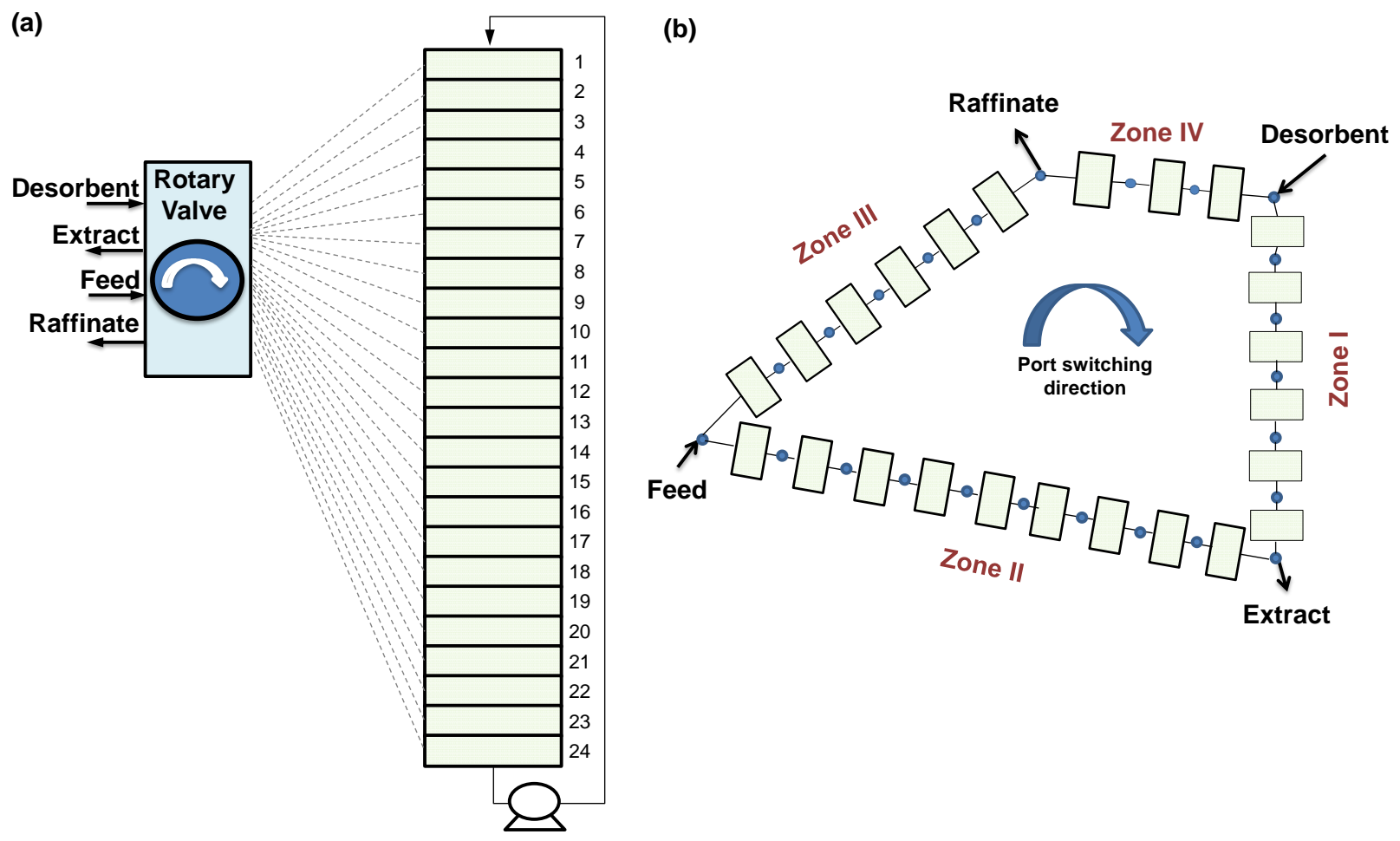

Figure 4. Schematic of the SMB process considered in this work. (a) 24-column SMB chamber, (b) the configuration of the zones I/II/III/IV with a 6/9/6/3 column arrangement. 

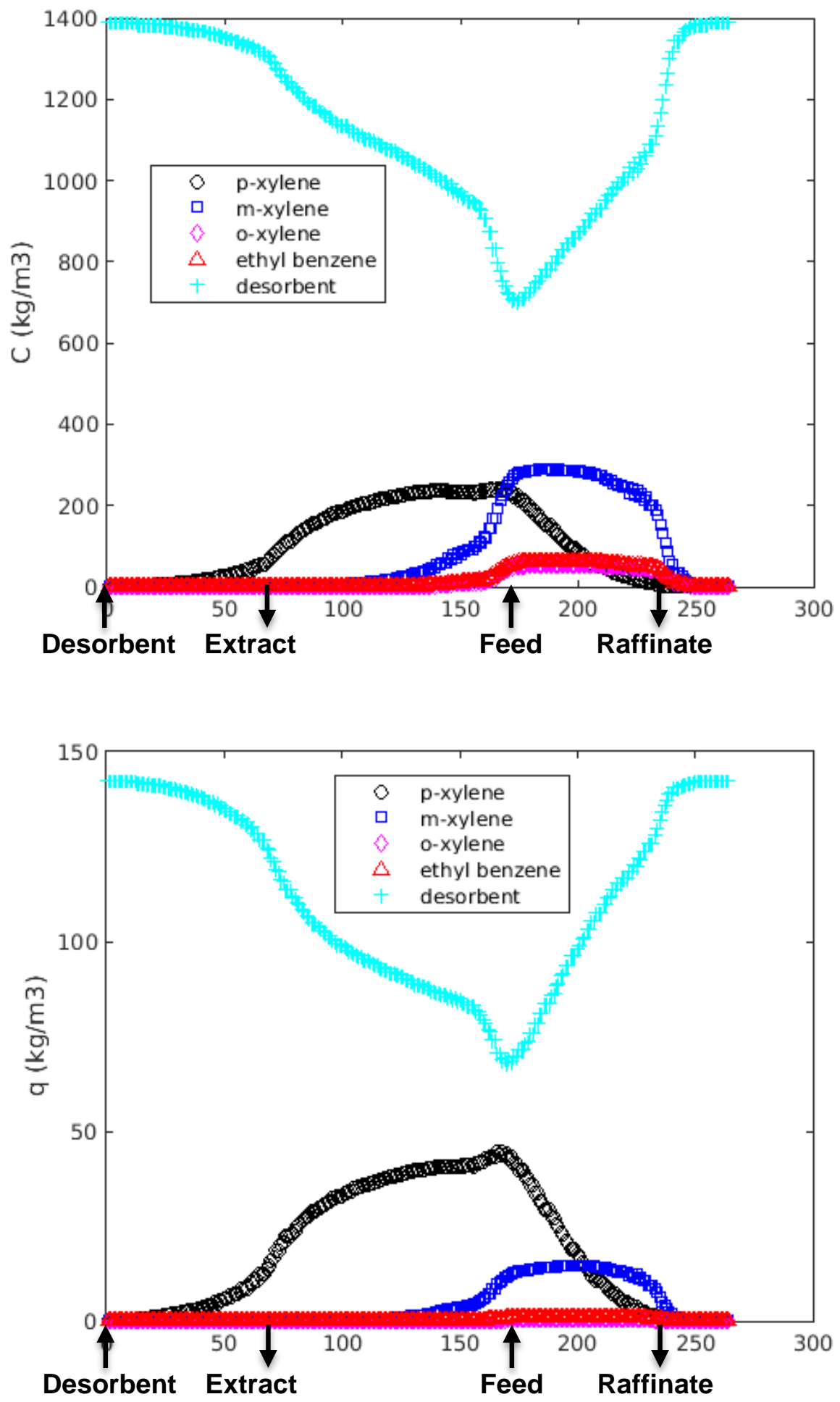

Figure 5. Cyclic steady-state concentration and loading profiles at the end of each cycle for different components for MWW zeolite at the optimum conditions for 24-column SMB process with 6/9/6/3 configuration. $x$-axis shows the discretized elements (11 discretization for each column, total 264 elements). 


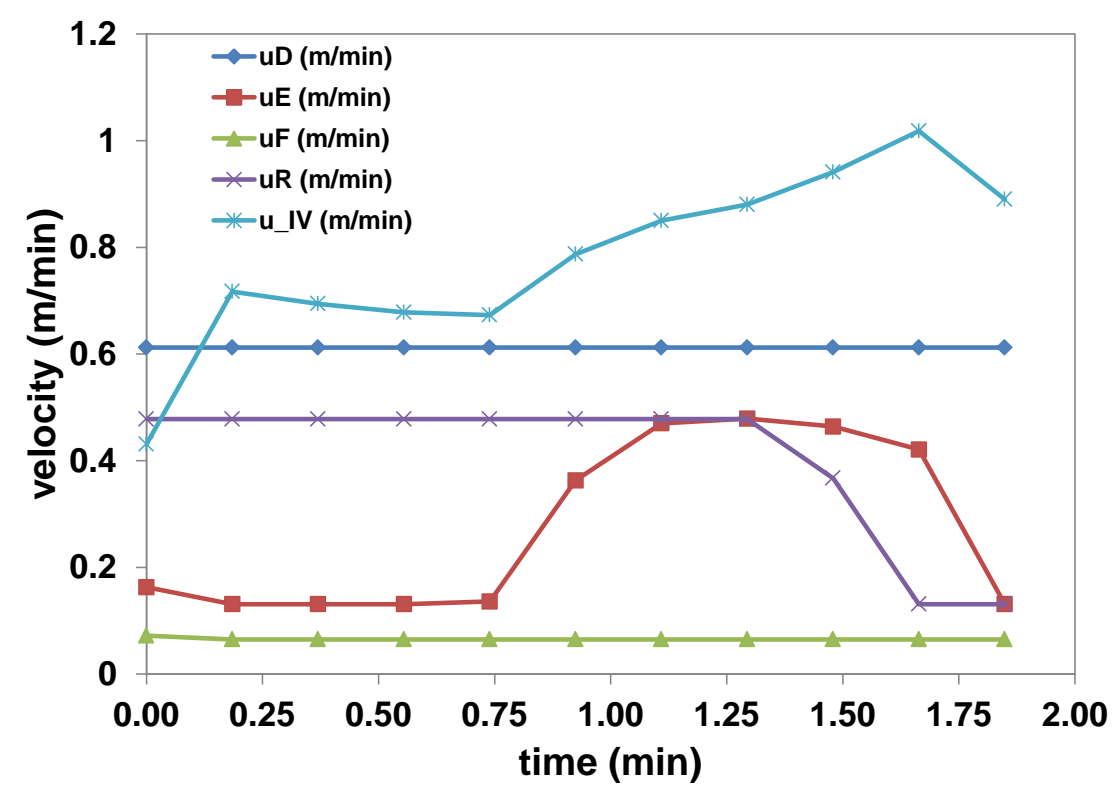

Figure 6. Optimum incoming and outgoing stream velocities for MWW. uD, UE, uF, and uR represent the stream velocities of the desorbent, extract, feed, and raffinate, respectively. uIV is the velocity of the fluid stream inside the zone IV. 

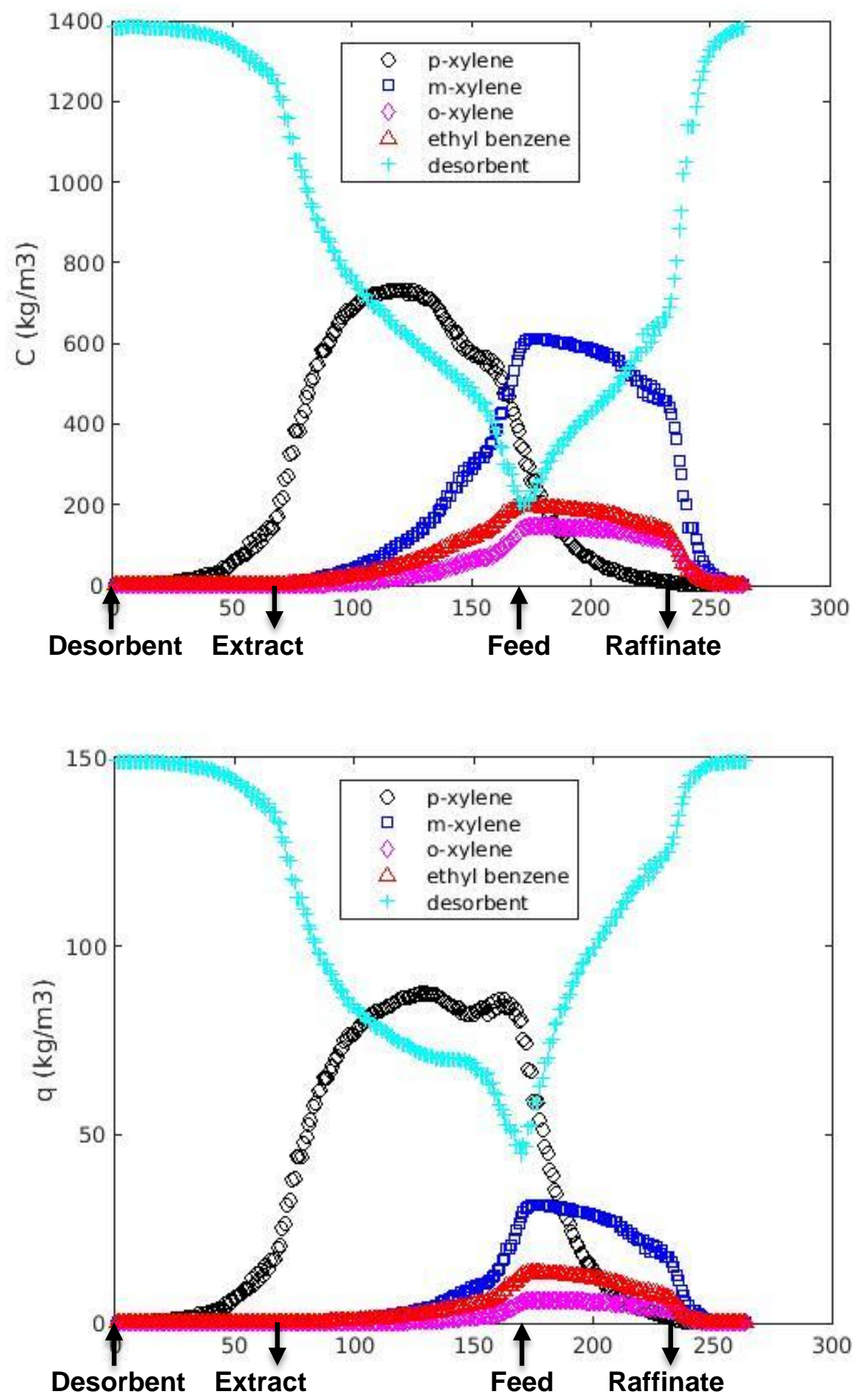

Figure 7. Cyclic steady-state concentration and loading profiles at the end of each cycle for different components for Y-zeolite at the optimum conditions for 24-column SMB process with 6/9/6/3 configuration. $x$-axis shows the discretized elements $(Z=11$ for each column, total 264 elements). 


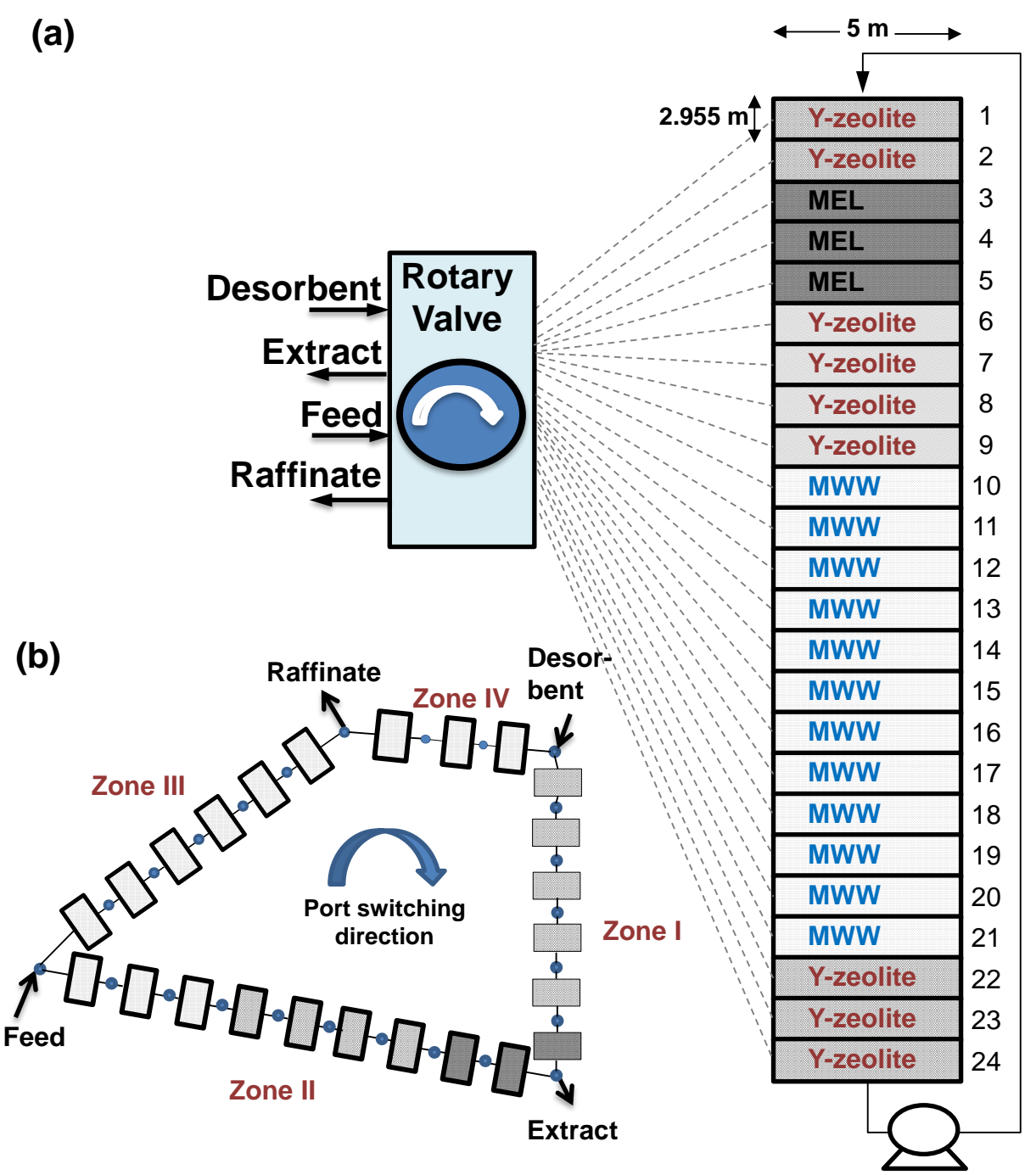

(c)

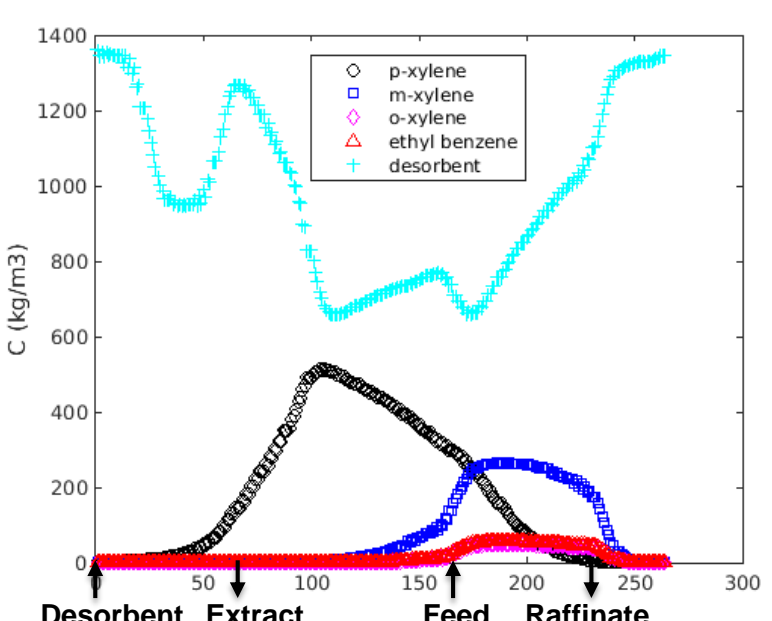

Desorbent Extract Feed Raffinate

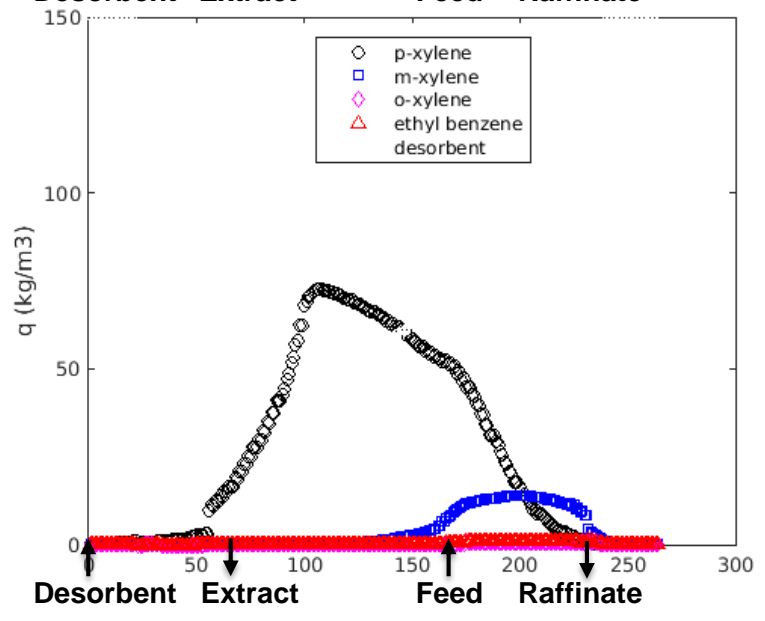

Figure 8. Design of 24-column SMB process with multiple zeolites in 6/9/6/3 configuration. (a) optimal SMB configuration (columns 1-2 use Y-zeolite, columns 3-5 use MEL, columns 6-9 use Y-zeolite, columns 10-21 use MWW, and columns 22-24 use Y-zeolite); (b) a representative zone configuration, which changes after every switching time; and, (c) optimal concentration profiles along the length of the SMB chamber at the end of each cycle. 
(a) Sensitivity on purity

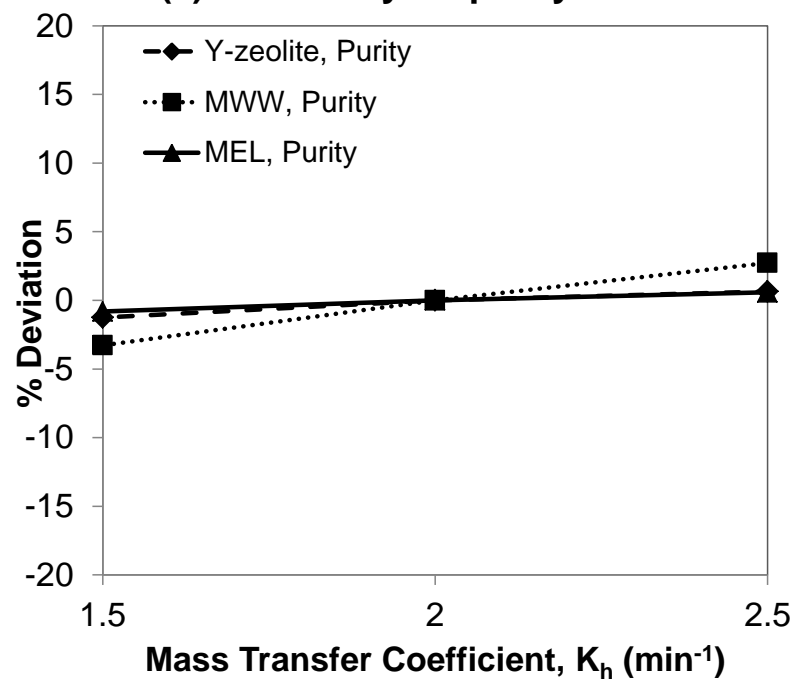

(b) Sensitivity on profit

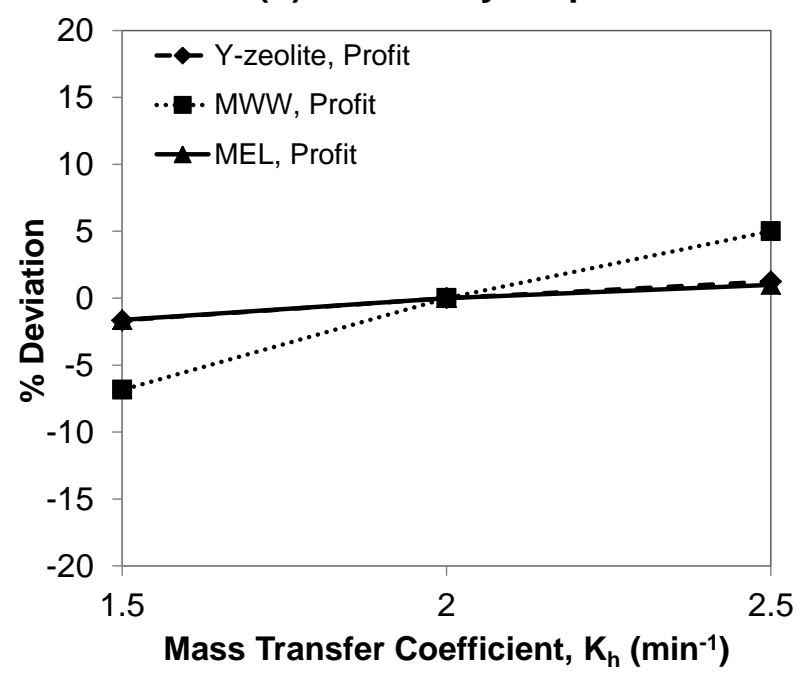

Figure 9. Sensitivity of (a) purity and (b) profit of SMB-based xylene separation on mass transfer rate. The \%deviation is measured by considering $K_{h}=2 \mathrm{~min}^{-1}$ to be the base case. 


\section{List of Tables}

1. Physical properties of xylene isomers and components in mixed xylenes.

2. Base investment and operating costs, and utility consumption, and product prices.

3. Top shape-selective zeolites for $p$-xylene separation.

4. Adsorption isotherm parameters considered for the study. 
Table 1. Physical properties of xylene isomers and components in mixed xylenes (Baertsch et al., 1996; Washburn, 2003).

\begin{tabular}{ccc}
\hline & $\begin{array}{c}\text { Boiling point } \\
\text { a }\end{array}$ & $\begin{array}{c}\text { Kinetic diameter, } \\
k_{c}[\AA]\end{array}$ \\
\hline$p$-xylene & 411.5 & 5.85 \\
$m$-xylene & 412.3 & 6.80 \\
$o$-xylene & 417.6 & 6.80 \\
ethylbenzene & 409.7 & 6.00 \\
\hline athese boiling points correspond to a pressure of 1 bar.
\end{tabular}


Table 2. Base investment and operating costs, and utility consumption, and product prices.

\begin{tabular}{|c|c|c|c|}
\hline Description & Notation & & Unit \\
\hline \multicolumn{4}{|c|}{ Base Parameters } \\
\hline$p$-xylene product capacity & $F_{\text {base }}$ & 700,000 & MTA \\
\hline Investment cost & & & \\
\hline Parex unit (million \$ U.S.) & $F C I_{\text {base }}$ & 127.1 & \\
\hline Utility consumption & $U F_{\text {base }}$ & & \\
\hline Electric power & & 5300 & $\mathrm{~kW}$ \\
\hline Medium-pressure steam & & 0.0055 & metric ton/s \\
\hline Cooling water & & 0.05 & $\mathrm{~m}^{3} / \mathrm{s}$ \\
\hline Fuel fired & & 0.14 & million Btu/s \\
\hline \multicolumn{4}{|c|}{ Prices } \\
\hline Unit utility cost & $U C$ & 0.10 & $\$ / \mathrm{kg} p$-xylene \\
\hline Electricity & & 0.07 & $\$ / \mathrm{kWh}$ \\
\hline Medium-pressure steam & & 6 & $\$ /$ ton \\
\hline Cooling water & & 0.001 & $\$ /$ ton \\
\hline Fuel fired & & 2.94 & \$/million Btu \\
\hline Product $p$-xylene & $P$ & 0.894 & $\$ / \mathrm{kg}$ \\
\hline
\end{tabular}


Table 3. Top shape-selective zeolites for $p$-xylene separation.

\begin{tabular}{|c|c|c|c|c|c|c|c|}
\hline \multirow{2}{*}{$\begin{array}{l}\text { Framework } \\
\text { type }\end{array}$} & \multirow[b]{2}{*}{ Zeolite } & \multirow{2}{*}{$\begin{array}{c}\text { Shape } \\
\text { selectivity of } \\
p \text {-xylene, } S\end{array}$} & \multirow{2}{*}{$\begin{array}{l}\text { Largest } \\
\text { cavity } \\
\text { diameter } \\
\text { LCD }[\AA]\end{array}$} & \multirow{2}{*}{$\begin{array}{c}\text { Pore } \\
\text { limiting } \\
\text { diameter, } \\
\text { PLD }[\AA]]\end{array}$} & \multicolumn{3}{|c|}{$\begin{array}{l}\text { Portal activation energies, } E_{a} \\
{[\mathrm{~J} / \mathrm{mol}]}\end{array}$} \\
\hline & & & & & $p$-xylene & $m$-xylene & $O$-xylene \\
\hline OBW & OSB-2 & 0.96 & 9.9 & 5.3 & 0 & 8540 & 7925 \\
\hline MEL & ZSM-11 & 0.95 & 8.4 & 5.7 & 0 & 6888 & 8113 \\
\hline MWW & MCM-22 & 0.92 & 10.3 & 5.2 & 0 & 5789 & 7405 \\
\hline MTT & ZSM-23 & 0.92 & 5.7 & 5.7 & 0 & 6838 & 5914 \\
\hline OWE & UiO-28 & 0.87 & 6.4 & 4.4 & 0 & 4879 & 5341 \\
\hline FER & Ferrierite & 0.81 & 7.0 & 5.3 & 0 & 4071 & 4259 \\
\hline SZR & SUZ-4 & 0.8 & 6.9 & 5.3 & 0 & 4130 & 3826 \\
\hline $\mathrm{IMF}$ & IM-5 & 0.78 & 8.0 & 5.9 & 0 & 3469 & 4283 \\
\hline TON & Theta-1 & 0.72 & 5.7 & 5.7 & 0 & 3610 & 2868 \\
\hline LAU & Laumontite & 0.71 & 5.5 & 2.8 & 831 & 10830 & 13400 \\
\hline
\end{tabular}




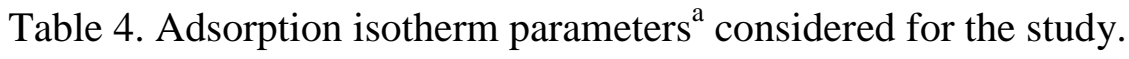

\begin{tabular}{|c|c|c|c|c|c|c|}
\hline Zeolite & $\begin{array}{c}q^{\max } \\
(\mathrm{kg} / \mathrm{kg})\end{array}$ & $\begin{array}{c}K_{p X} \\
\left(\mathrm{~m}^{3} / \mathrm{kg}\right)\end{array}$ & $\begin{array}{c}K_{m X} \\
\left(\mathrm{~m}^{3} / \mathrm{kg}\right)\end{array}$ & $\begin{array}{c}K_{O X} \\
\left(\mathrm{~m}^{3} / \mathrm{kg}\right)\end{array}$ & $\begin{array}{c}K_{E B} \\
\left(\mathrm{~m}^{3} / \mathrm{kg}\right)\end{array}$ & $\begin{array}{c}K_{E B} \\
\left(\mathrm{~m}^{3} / \mathrm{kg}\right)\end{array}$ \\
\hline $\begin{array}{c}\text { K- } \\
\text { exchanged } \\
\text { Y-zeolite } \\
\end{array}$ & $\begin{array}{c}0.1303 \text { (xylenes) } \\
0.1077 \text { (pDEB) }\end{array}$ & 1.0658 & 0.2299 & 0.1884 & 0.3037 & 1.2935 \\
\hline $\begin{array}{c}\text { MWW } \\
(\mathrm{MCM}-22)\end{array}$ & $\begin{array}{c}0.07914(p X, m X) \\
0.0467(o X, E B) \\
0.1029(p D E B)\end{array}$ & 0.8488 & 0.20 & 0.07 & 0.07 & 0.33 \\
\hline $\begin{array}{c}\text { MEL } \\
(\mathrm{ZSM}-11)\end{array}$ & $\begin{array}{c}0.04218(p X, p \mathrm{DEB}) \\
0.03816(m X) \\
0.00703(o X, E B)\end{array}$ & 1.1 & 0.67 & 0.50 & 0.50 & 1.29 \\
\hline
\end{tabular}

${ }^{\mathrm{a}} q^{\max }$ is the saturation capacity $(\mathrm{kg} / \mathrm{kg}), K_{i}$ is the Langmuir isotherm constant for component $i, p X$ is $p$-xylene, $m X$ is $m$-xylene, $o X$ is $o$-xylene, and $E B$ is ethylbenzene. 